\title{
Synthesis of seven membered oxacycles: Recent developments and new approaches
}

\author{
Victoria Sinka, ${ }^{[b]}$ Víctor S. Martín, ${ }^{[a]}$ Daniel A. Cruz ${ }^{*[a]}$, and Juan I. Padrón ${ }^{*[b]}$ \\ [a] Dr. D. A. Cruz, Prof. V. S. Martín \\ Instituto Universitario de Bio-Orgánica "Antonio González", "Síntesis Orgánica Sostenible, Unidad Asociada al CSIC”, Departamento de Química Orgánica \\ Universidad de La Laguna \\ C/ Francisco Sánchez 2, 38206 La Laguna, Tenerife, Islas Canarias, Spain \\ E-mail: dcruzper@ull.edu.es; https://www.ipna.csic.es/ \\ [b] M.Sc. V. Sinka, Dr. J. I. Padrón \\ Molecular Sciences Department, Instituto de Productos Naturales y Agrobiología, Consejo Superior de Investigaciones Científicas (IPNA-CSIC) \\ Avda. Astrofísico Francisco Sánchez 3, 38206 La Laguna, Tenerife, Islas Canarias, Spain \\ E-mail: jipadron@ipna.csic.es; https://www.ipna.csic.es/
}

\begin{abstract}
This review focuses on recent advances in the synthesis of seven-membered ring oxacycles, whether saturated, unsaturated, fused or isolated. We cover a remarkable variety of strategies and methods developed during the past two decades, based mainly on cyclizations, ring-closing metathesis, conjugate additions and ring expansions. The cyclizations can be generated directly or triggered through an oxocarbenium ion, carbocation or iminium-type species. Also discussed are ring-closing metatheses and conjugate additions, in which the precursor has the functionalities and correct stereochemistry of the final sevenmembered ring oxacycle. Finally, examples of ring expansions are described, predominantly involving cyclopropanes and epoxides. These cases include reactions governed by the intermediate species and others where the precursor holds the stereochemical information for the final oxacycle.
\end{abstract}

\section{Introduction}

Small molecules and heterocycles with polycyclic fused rings from terrestrial and marine natural products are biologically active motifs valuable in the pharmaceutical context. ${ }^{[1-3]}$ These compounds can be formed from oxacycles of several sizes. Among the family of medium-size oxacycles, those with sevenmembered rings show a range of biological activities as antifungal, modulators of biological systems, and potential Alzheimer drugs, among others, ${ }^{[4]}$ both alone or forming part of more complex structures. Furthermore, these oxacycles are present in the polyfunctionalized cyclic ethers of ladder marine toxins, ${ }^{[5]}$ such as ciguatoxins, the major causative agents of ciguatera seafood poisoning. Several haptens, including oxepanes and oxepenes with other type of oxacycles, have been therefore designed to try and solve the problems surrounding anticiguatoxin antibodies. ${ }^{[6]}$ For these reasons, many synthetic chemists have developed new strategies and methodologies to gain access to these sevenmembered ring oxacycles and advance their applications in the synthesis of natural products and their analogs, as well as in their biological studies. The main synthetic strategies discussed in this manuscript are mainly based on cyclization, ring-closing metathesis and ring expansion.

\begin{abstract}
Juan I. Padrón received his B.Sc. in Chemistry from the University of La Laguna, Tenerife, Spain in 1990, and obtained his Ph.D. in Organic Chemistry in 1995 from the same university, working on the synthesis and stereochemical studies of saccharides under the guidance of Professor Jesús Trujillo Vázquez. He then spent two years (1996-1997) at the University of Columbia as a postdoctoral fellow with Professor

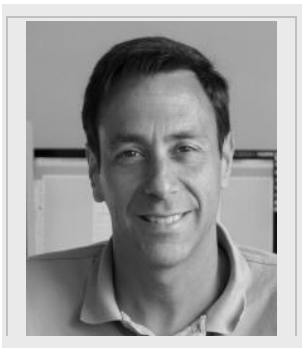

Samuel J. Danishefsky, working on natural product synthesis. In 1998, he returned to the Canary Islands, and joined the laboratory of Professor Jaime Bermejo (CSIC). In 2004, he won a contract under the Ramón y Cajal program created to boost Spanish science, working with Víctor S. Martín at the University of La Laguna. In 2008, he became a tenured scientist at the Instituto de Productos Naturales y Agrobiología-CSIC, Tenerife, Spain. He was promoted to Senior Research Scientist in 2020. His interests include sustainable metal catalysis, new reaction methodologies, and their applications to natural product synthesis.
\end{abstract}

Daniel A. Cruz obtained his B.Sc. in Chemistry and his M.Sc. in Chemistry Research in 2011 and 2012 respectively, from the University of La Laguna. Then, in 2017, he received his Ph.D. in Chemistry and Chemical Engineering from the same university, for his work in the development of synthetic methodology to generate oxacycles and alkyl halides by means of sustainable metals. This work was conducted under the supervision of Dr. Juan I. Padrón and Professor Víctor S. Martín

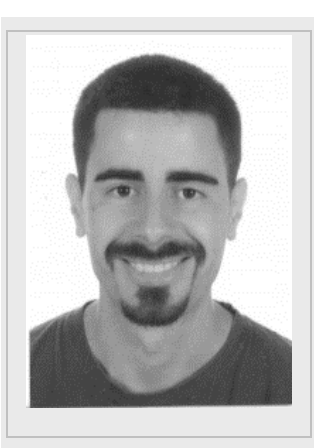

García. Then, during the years 2017-2019 he worked in different groups, the first being led by Professor José J. Fernández Castro from the University of La Laguna, where he worked on the extraction of marine natural products and preparation of pharmaceutical dosages against osteoporosis. Next, he moved to the University of Aarhus to work in Dr. Thomas Bjørnskov Poulsen's group, advancing the synthesis of natural product analogs. Finally, he joined the pharmaceutical company Ceamed S.A. to work on the development of small molecules with anti-cancer activity. Currently, he is 
linked again to the University of La Laguna as researcher under the Agustín de Bethencourt initiative.

Victoria Sinka obtained her B.Sc. and M.Sc. in Chemistry from the University of La Laguna in 2015 and 2016, respectively. Then, in 2016, she began her Ph.D. studies in Chemistry and Chemical Engineering from the same university, working on the synthesis of heterocycles of different sizes using iron(III) salts. This is being conducted under the supervision of Dr. Juan I. Padrón.

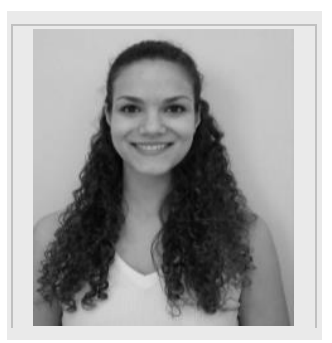

Víctor S. Martín was born in La Palma (Canary Islands), Spain, and received his Ph.D. degree from the Universidad de La Laguna, Tenerife, in 1978 under the guidance of Professors Antonio González, Julio D. Martín and Manuel Norte. From 1980-82 he was a postdoctoral fellow with Professor K. Barry Sharpless in Stanford University and the Massachusetts Institute of Technology. He moved to the University of La Laguna as Associate Professor in

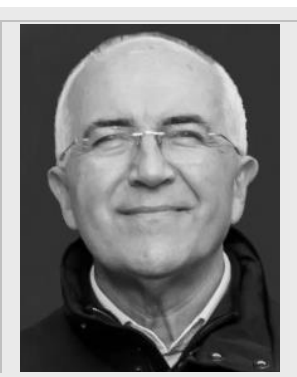
1984. In 1998 was promoted to Scientific Researcher of the CSIC of Spain. Since 1992 he holds a Full Professor position at Universidad de La Laguna. His research interest includes asymmetric synthesis, methodology and total synthesis of bioactive natural products. $\mathrm{He}$ is the Director of the Institute of Bio-Organic Antonio González (IUBO-AG) and recipient of the 2016 Felix Serratosa Medal awarded by the Organic Chemistry Group (GEQOR) of the Spanish Royal Society of Chemistry.

\section{Hetero-cyclization methods}

In the following sections, we describe recently developed methodologies to synthesize seven-membered cyclic ethers. The examples in 2.1 section are divided according to the type of catalyst (Lewis and protic acid) used. Methodologies in which a pericyclic reaction is the key step have been also included as well as procedures relying in basic conjugated additions.

\subsection{Cyclization by means of acids}

The use of Lewis acids in the cyclic ether synthesis is one of the standard tools, due to its wide variety and the wide range of reactions that promote. However, this strategy remains less explored when oxepanes and oxepenes are the synthetic target. ${ }^{[7]}$ In fact, during the last two decades, few publications have used this strategy as the key step.

One example using this approach was published in 2000 by McDonald and co-workers. In this case, the use of $\mathrm{BF}_{3} \cdot \mathrm{OEt}_{2}$ as Lewis acid was essential to promote the endo oxacyclization reaction that provides the final oxepanes (Scheme 1). ${ }^{[8]}$

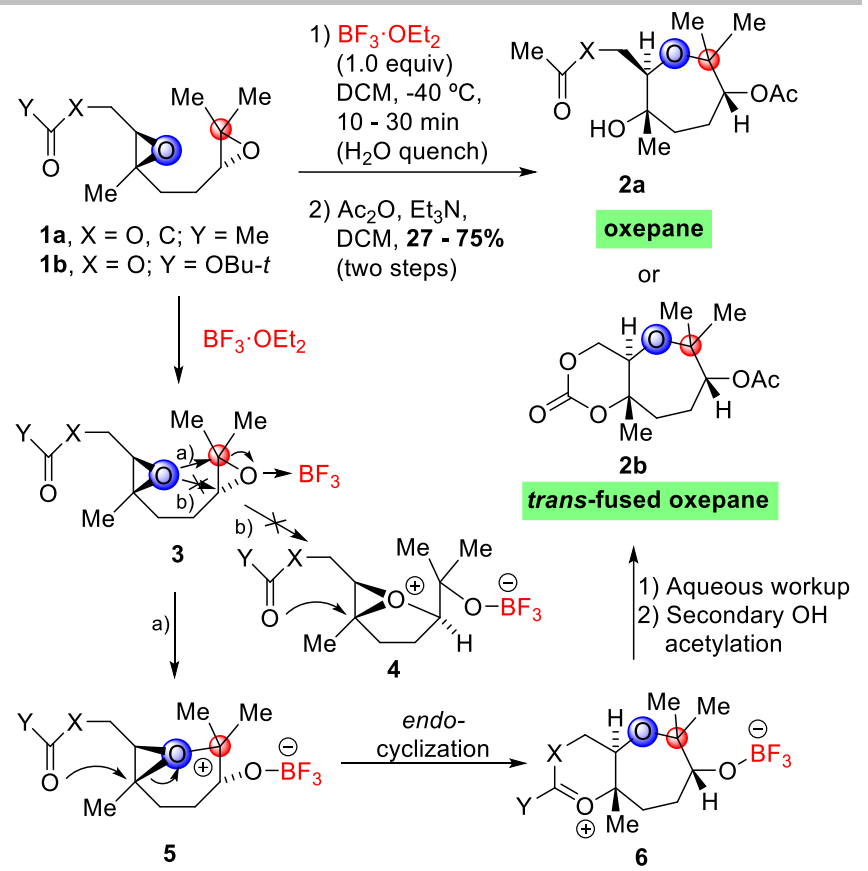

Scheme 1. $\mathrm{BF}_{3} \cdot \mathrm{OEt}_{2}$ promoted endo cyclization in the synthesis of functionalized oxepanes 2. Adapted from ref. ${ }^{[8]}$

$\mathrm{BF}_{3} \cdot \mathrm{OEt}_{2}$-activated terminal epoxide was nucleophilically attacked by the internal one yielding the less strained intermediate 5. Aqueous work-up provided either isolate oxepane $\mathbf{2 a}$ or the fused alternative $\mathbf{2 b}$.

Another method of cyclization based on the use of Lewis acids was reported in 2002 by Martín and co-workers, and successfully applies the Nicholas reaction towards the synthesis of oxepenes (Scheme 2). ${ }^{[9]}$

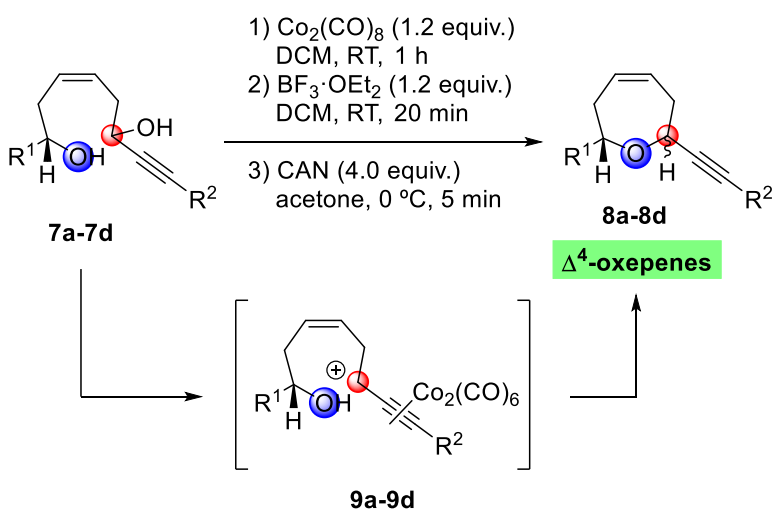

8a: $\mathrm{R}^{1}=\mathrm{Me} ; \mathrm{R}^{2}=n-\mathrm{C}_{5} \mathrm{H}_{11} ; \mathbf{7 0 \%}$ (overall), cis only

8b: $\mathrm{R}^{1}=\mathrm{CH}=\mathrm{CHCO}_{2} \mathrm{Me} ; \mathrm{R}^{2}=\mathrm{CH}_{2} \mathrm{OBn} ; 73 \%$ (overall), cis only

8c: $\mathrm{R}^{1}=\mathrm{R}_{\mathrm{O}}: \mathrm{R}^{2}=\mathrm{H} ; \mathbf{6 8 \%}$ (overall), cis/trans mixture
$\mathrm{R}_{2} \mathrm{OBn} ; \mathbf{7 9} \%$ (overall), cis/trans mixture

Scheme 2. Synthesis of $\Delta^{4}$-oxepenes through intramolecular Nicholas reaction. Adapted from ref. ${ }^{[9]}$

Once the appropriate substrates $\mathbf{7 a - 7 d}$ are prepared, the cobaltalkyne complex is formed and the Lewis acid promotes the generation of the carbocation at the propargylic position, so as to 
undergo the nucleophilic attack from the free alcohol that yields the desired oxepenes $\mathbf{8 a}-\mathbf{8 d}$.

Other Lewis acids have been used to promote the formation of oxepenes. In 2008, the work by $\mathrm{Yu}$ and co-workers took advantage of the properties of TMSOTf for the cyclization of allenes in a one-pot procedure. ${ }^{[10]}$

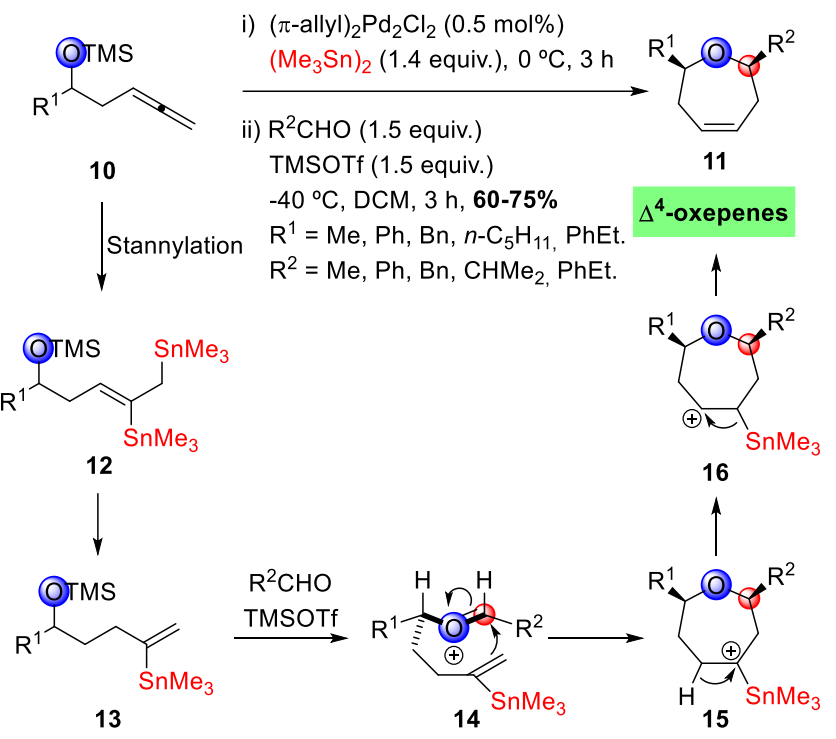

Scheme 3. Synthesis of $\Delta^{4}$-oxepenes by a TMSOTf promoted cyclization. Adapted from ref. ${ }^{[10]}$

This tentative approach to the cyclization process was inspired by previous works by Overman and co-authors, ${ }^{[11]}$ where once the initial substrate has been transformed into the tin-derivative 13, the Lewis acid promotes the condensation and cyclization process to generate the cation 15 . Finally, the cation is stabilized by the tin $\beta$-effect, ${ }^{[12]}$ allowing the intermediate 16 to release the tin moiety and generate the final oxepene $\mathbf{1 1}$ (Scheme 3).

In 2018, Padrón and co-workers presented a study of the properties of iron-based Lewis acids to catalyze the synthesis of $\Delta^{4}$-2,7-disubstituted oxepenes (Scheme 4) ${ }^{[13]}$

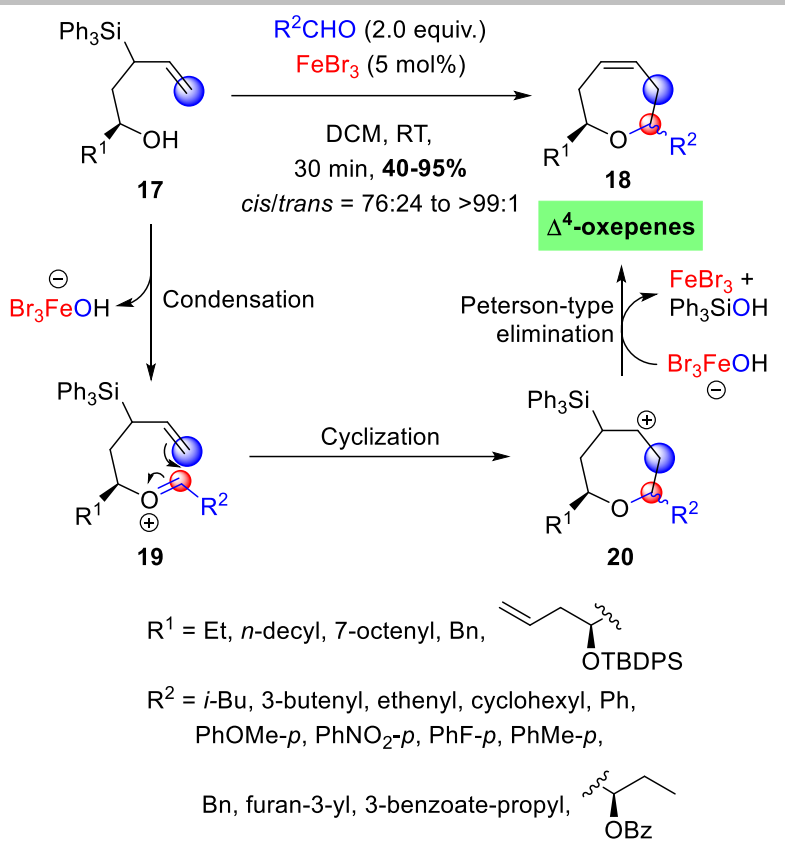

Scheme 4. $\mathrm{FeBr}_{3}$ catalyzed synthesis of $\Delta^{4}$-2,7-disubstituted oxepenes. Adapted from ref. ${ }^{[13]}$

However, not only does the ability of $\mathrm{FeBr}_{3}$ to catalyze the process take the lead, but the choice of appropriate substrate also plays a central role. Thus, as the mechanism indicates, the first stage of this process is the condensation between the $y$-triphenylsilyl bishomoallylic alcohol $\mathbf{1 7}$ and the aldehyde, where the Lewis acid catalyzes the event. Next, a classical Prins cyclization step generates de cation $\mathbf{2 0}$, which is stabilized by the silicon $\beta$ effect. ${ }^{[12]}$ Finally, this intermediate evolves through a Petersontype elimination, concluding the cascade of events that ends in the generation of the $\Delta^{4}$-2,7-disubstituted oxepene 18 in one step, with very good yields.

In the same year Sun and co-workers reported work focused on the catalytic use of the heteropoly acid $\mathrm{H}_{3} \mathrm{PW}_{12} \mathrm{O}_{40} \cdot{ }^{[14]}$ Here, the catalyst is prepared and the experimental conditions are optimized, pointing out its advantages as a versatile catalyst due to its multiple active sites (Scheme 5). ${ }^{[15]}$

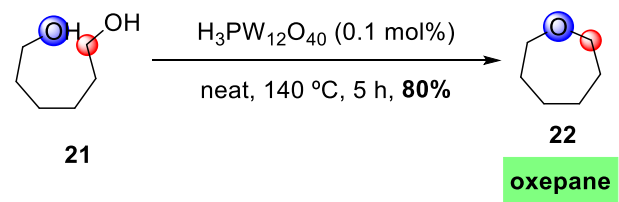

Scheme 5. $\mathrm{H}_{3} \mathrm{PW}_{12} \mathrm{O}_{40}$ catalyzed cyclodehydration conditions in the synthesis of oxepane 22. Adapted from ref. ${ }^{[14]}$

As the other examples presented, the cyclodehydration of diol 21 only demands a $0.1 \mathrm{~mol} \%$ of catalyst load, and no solvent is required to obtain the desired oxepane 22 in good yield.

Another publication relevant to this section comes from Huang and co-workers, and presents a catalytic use of $\mathrm{Zn}(\mathrm{OTf})_{2}$ as Lewis acid in the cyclization of alkynols with $N, \mathrm{O}$-aminals. ${ }^{[16]}$ 


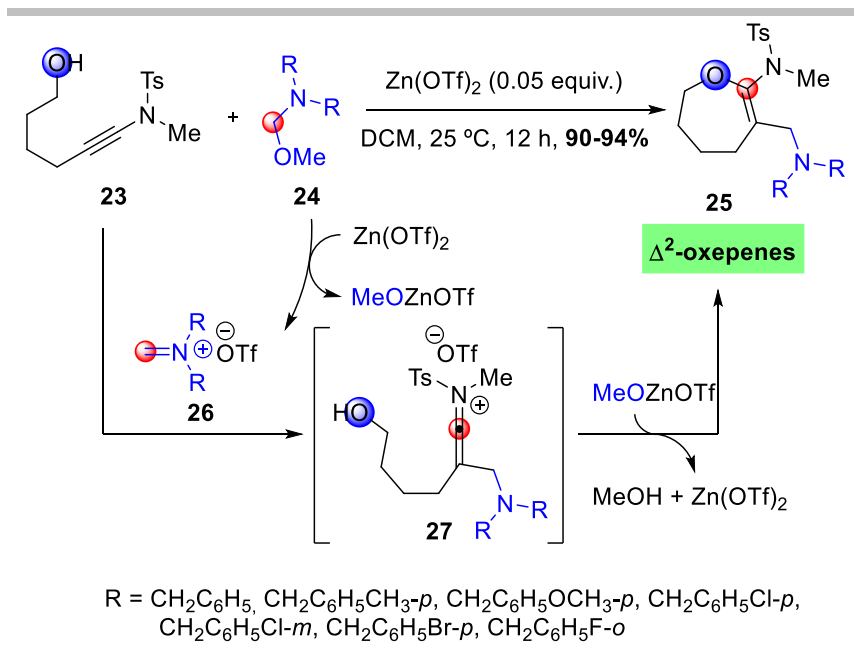

Scheme 6. $\mathrm{Zn}(\mathrm{OTf})_{2}$ catalyzed electrophilic aminomethyloxygenative cyclization process. Adapted from ref. ${ }^{[16]}$

Following Scheme 6, the mechanism starts when the $\mathrm{Zn}(\mathrm{OTf})_{2}$ reacts with the amine $\mathbf{2 4}$ to generate the iminium 26 . Then, this salt is attacked by the alkyne $\mathbf{2 3}$, yielding the allenic intermediate 27. Finally, the nucleophilic oxygen attacks the allenic central carbon to give the final oxepenes 25 , while the $\mathrm{Zn}(\mathrm{OTf})_{2}$ is regenerated, leaving $\mathrm{MeOH}$ as the only byproduct.

Finally, the last approach covered in this section was developed by Chang and co-workers, where an intramolecular cyclization method catalyzed by a protic acid is presented (Scheme 7). ${ }^{[17]}$

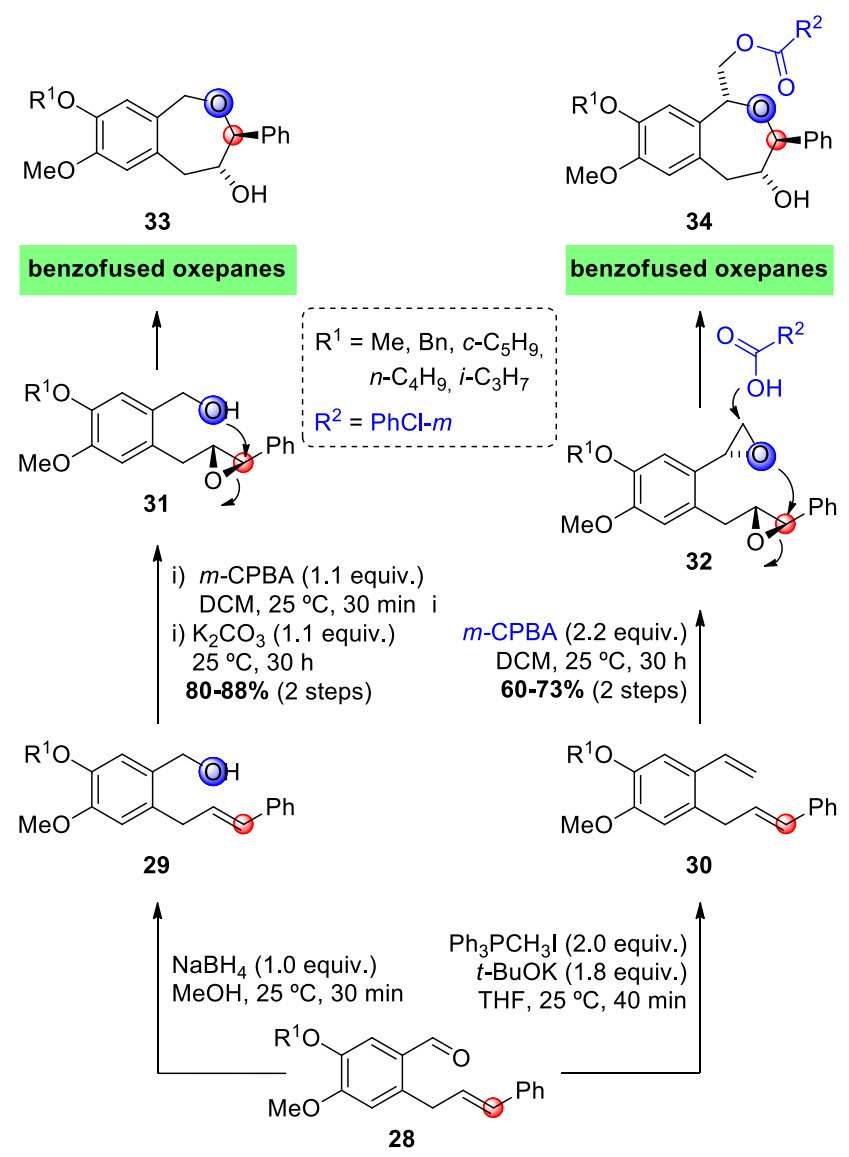

Scheme 7. Synthetic pathway for the oxidative annulation of substrate $\mathbf{2 8}$ Adapted from ref. ${ }^{[17]}$
Their work is based on the use of meta-chloroperoxybenzoic acid (mCPBA) to generate epoxides at the double bonds present in substrates $\mathbf{2 9}$ and $\mathbf{3 0}$. Following the two routes in Scheme 7, each epoxide is then selectively opened during the final cyclization process, providing the final benzofused oxepanes as a racemic mixture, but with total trans diastereoselection.

\subsection{Methods including a pericyclic reaction}

This section includes two interesting cyclization examples where a pericyclic reaction takes place.

The strategy of the work presented by Mukai and co-workers in 2004 was to achieve a base-promoted cyclization of allenealcohols, which opens a route to medium-size oxacycles, including the seven-membered ones. ${ }^{[18]}$ The process follows a method they previously developed, ${ }^{[19]}$ and starts with the propargylic alcohol 35 (Scheme 8).

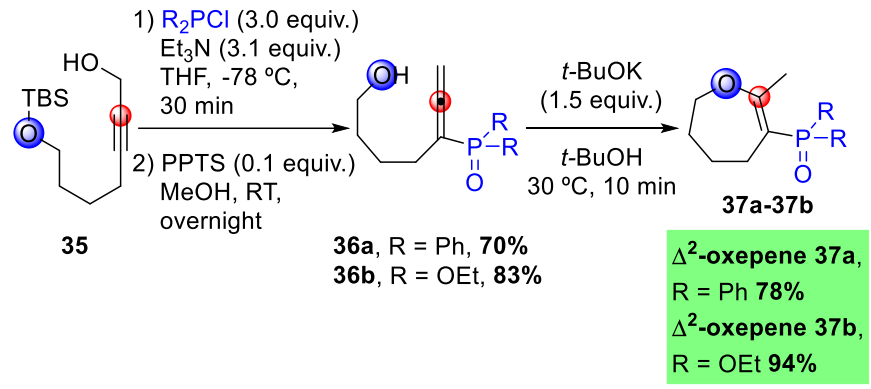

Scheme 8. Cyclization process to synthesize oxepenes $\mathbf{3 7 a}$ and $\mathbf{3 7 b}$. Adapted from ref. ${ }^{[18]}$

This alcohol is treated with $\mathrm{R}_{2} \mathrm{PCl}$ to induce a [2,3]-sigmatropic rearrangement that forms the corresponding silyl-protected allenylphosphines, which are deprotected in acidic conditions to yield the allene-alcohols $\mathbf{3 6}$ ( $\mathbf{a}$ and $\mathbf{b}$ ). These allenes were then cyclized with endo selectivity using $\mathrm{KOBu}-t$ to generate the oxepenes $\mathbf{3 7 a}$ and $\mathbf{3 7 b}$.

The next publication, by Mandal and co-workers, dates from 2007 and presents a completely different approach, generating oxepanes from $D$-glucose. ${ }^{[20]}$ Here, the key step to achieve the cyclization process is a 1,3-dipolar nitrone cycloaddition reaction. ${ }^{[21]}$

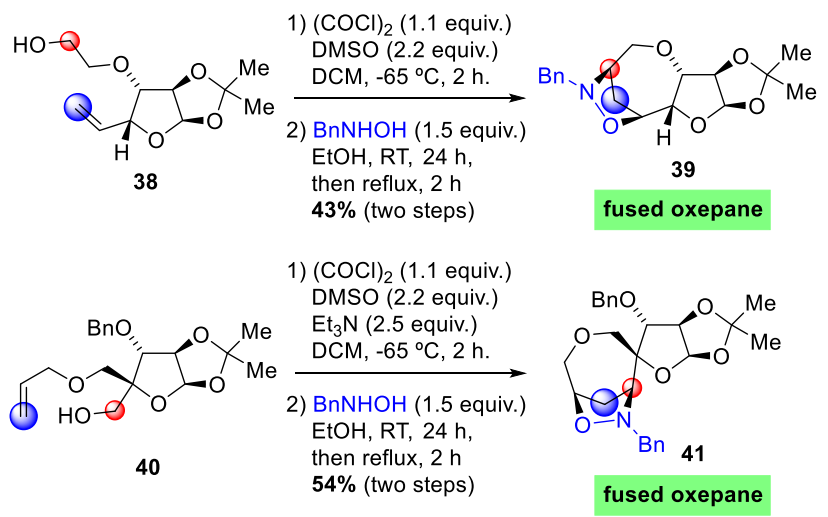

Scheme 9. Synthesis of oxepenes 39 and $\mathbf{4 1}$ through a 1,3-dipolar nitrone cycloaddition reaction. Adapted from ref. ${ }^{[20]}$ 
Both examples included in Scheme 9 are prepared following the same strategy. After oxidation of the alcohol group to an aldehyde, the crude is treated with the conditions for 1,3-dipolar nitrone cycloaddition. In the first step, the hydroxylamine $\mathrm{BnNHOH}$ reacts with the aldehyde to form the corresponding nitrone. Then, the cycloaddition takes place to generate the final fused oxepanes 39 and 41 .

\subsection{Conjugate addition reactions}

In 2014, Hong and colleagues reported the stereoselective synthesis of $\alpha, \alpha^{\prime}$-trans-oxepanes $\mathbf{4 4}$ through an organocatalytic oxa-conjugate addition reaction, promoted by the gemdisubstituent (Thorpe-Ingold) effect (Scheme 10). Medium-sized cyclic ethers $\mathbf{4 4}$ are achieved through an intramolecular oxaconjugate addition reaction, using $\alpha, \beta$-unsaturated aldehydes with a 1,3-dithiane group, which is one of the most effective group in the gem-disubstituent effect. The position of this 1,3-dithiane group was optimized and C4 on the aldehyde is the best position. Different $\alpha, \beta$-unsaturated aldehydes 42 with a variety of substituents at the $\mathrm{C} 2$ position were prepared and the reactions were run with $(R)-43(20 \mathrm{~mol} \%)$ and $\mathrm{BzOH}$, providing the $\alpha, \alpha^{\prime}$ trans-oxepanes 44 as the major diastereomers, with good stereoselectivity and yields. NMR experiments demonstrate that this organocatalytic oxa-conjugate addition is a kinetically controlled process. The major diastereomer $\alpha, \alpha^{\prime}$-trans-oxepane 44 is initially formed, but after $24 \mathrm{~h}$, the reaction provides a 1:1 mixture of $\mathbf{4 4}$ with the corresponding $\alpha, \alpha^{\prime}$-cis-oxepane. ${ }^{[22]}$

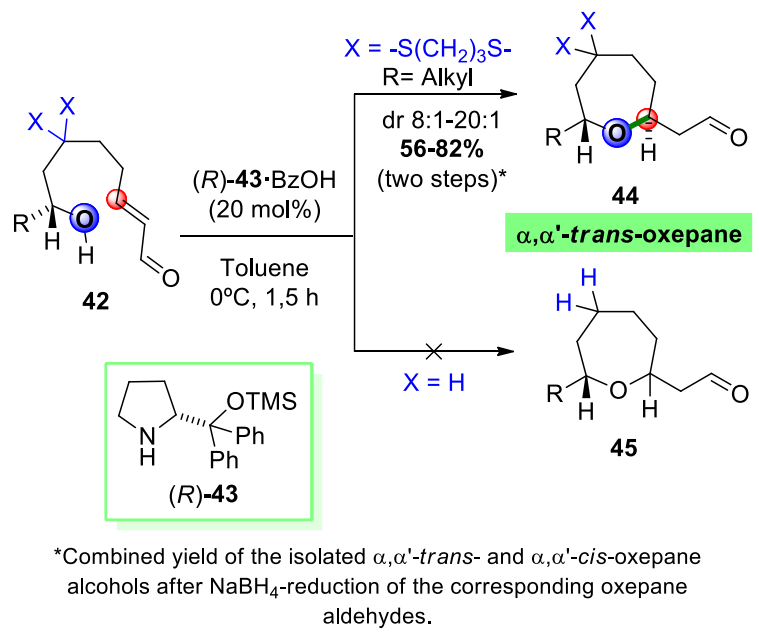

Scheme 10. Synthesis of $\alpha, \alpha$-trans-oxepanes 44 through an organocatalytic oxa-conjugate addition reaction promoted by the gem-disubstituent (Thorpe-Ingold) effect. Adapted from ref. ${ }^{[22]}$

An intramolecular Michael addition was used in the synthesis of bicyclic seven-membered oxacycle 47 . Precursor 46 can be accomplished using different starting materials, propargylic alcohol and furan through two alternatives routes (Scheme 11). The key step was the treatment of this precursor $\mathbf{4 6}$ with TBAF in order to remove the TBS group, obtaining the bicyclic compound 47 at a $63 \%$ yield, through an intramolecular Michael addition. Reduction of $\mathbf{4 7}$ with $\mathrm{Et}_{3} \mathrm{SiH}$ in the presence of TMSOTf gave lactone 48 in 53\%. Finally, the ring junction was determined by NMR experiments and established as trans-bicyclic lactone $\mathbf{4 8 ,}$ containing an oxepane ring. ${ }^{[23,24]}$

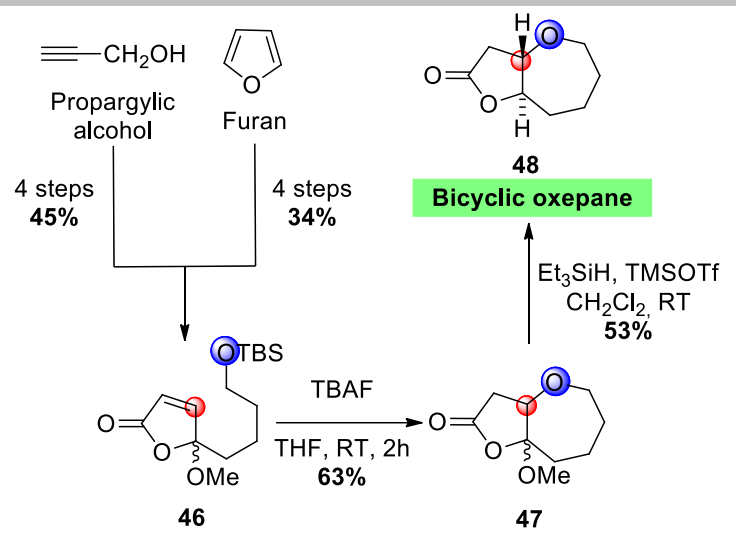

Scheme 11. Intramolecular Michael addition used in the synthesis of bicyclic seven-membered oxacycle 47 . Adapted from refs. ${ }^{[23,24]}$

\section{Oxidative-reductive and metal-promoted couplings cyclizations}

\subsection{Oxidative-reductive cyclizations}

Oxidative and reductive cyclizations are useful techniques to generate five- and six-membered oxacycles, ${ }^{[25]}$ however they are far less represented in the synthesis of seven-membered cyclic ethers.

One of these examples was developed by Nakata and co-workers back in the late 90 's. Here, the properties of $\mathrm{Sml}_{2}$ are exploited to generate a straightforward approach to the synthesis of transfused medium size polycyclic ethers. ${ }^{[26]}$

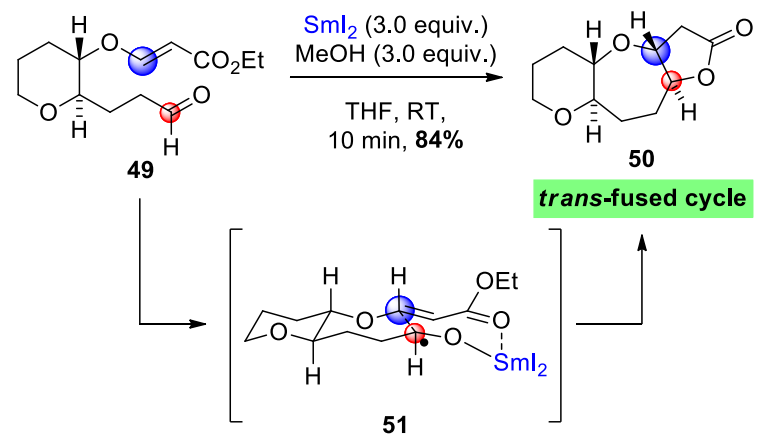

Scheme 12. Reductive cyclization process induced by $\mathrm{Sml}_{2}$ to provide the trans-fused tricycle 50. Adapted from ref.[26]

Following Scheme 12, it is easy to see how $\mathrm{Sml}_{2}$ has two roles in the cyclization reaction. The first is its ability to perform a single electron transfer to the aldehyde group, and the second is to chelate the resulting oxygen of the aldehyde and the ester, thus transferring the pre-organized trans disposition from the transition state $\mathbf{5 1}$ into the final oxepane $\mathbf{5 0}$.

Five years later, Sibi and co-workers developed a reductive cyclization-like strategy, where a radical intermediate was present again (Scheme 13). ${ }^{[27]}$ 


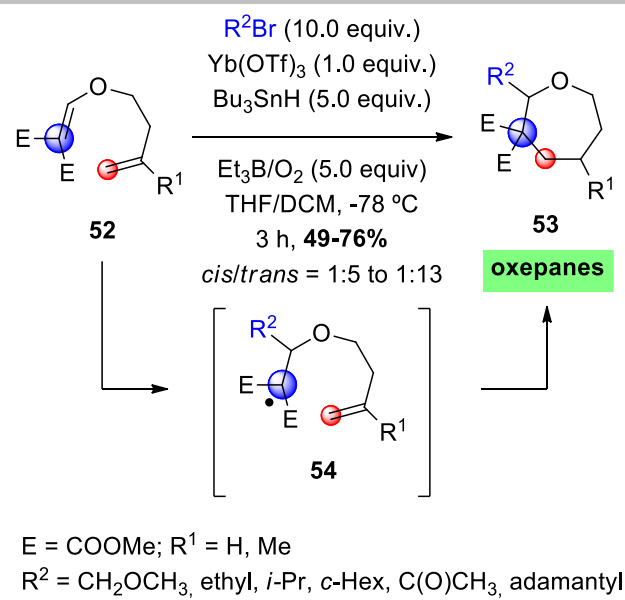

Scheme 13. Radical cyclization of the $\beta$-alkoxyalkylidenemalonate 52. Adapted from ref. ${ }^{[27]}$

This example was closer to a classical radical process, where a radical chain reaction takes place. Here, the low-temperature initiator $\mathrm{Et}_{3} \mathrm{~B} / \mathrm{O}_{2}$, the chain carrier $\mathrm{Bu}_{3} \mathrm{SnH}$, and the radical precursor $\mathrm{R}^{2} \mathrm{Br}$ launch the reaction to insert the $\mathrm{R}^{2}$ moiety on the malonate $\beta$ carbon, generating the radical intermediate 54 . Then, boosted by the use of $\mathrm{Yb}(\mathrm{OTf})_{3}$, the addition to the double bond completes the cyclization process with almost total endo selectivity and a remarkable trans/cis ratio.

\subsection{Cyclization based on metal-promoted couplings}

Since their discovery, transition metal-promoted couplings have become one of the top tier tools in organic synthesis. ${ }^{[28]}$ Propernamed methods like the couplings of Heck, ${ }^{[29]}$ Negishi, ${ }^{[30]}$ Stille, ${ }^{[31]}$ among many others, are studied and used every day to obtain a plethora of compounds. In this section, three different syntheses of seven membered oxacycles will be covered, all published in 2016.

The first approach is a work from Álvarez-Manzaneda and coworkers, where the use of an oxidative coupling strategy is the key to obtain oxepane terpenoids like 56a-56d (Scheme 14). ${ }^{[32]}$

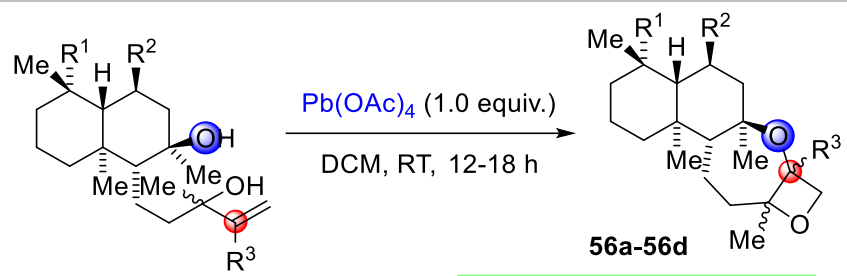

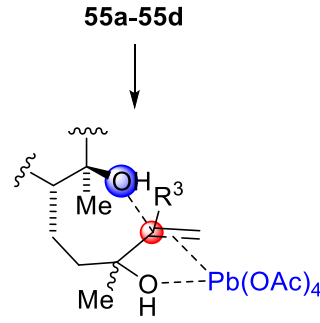

$57 a-57 d$

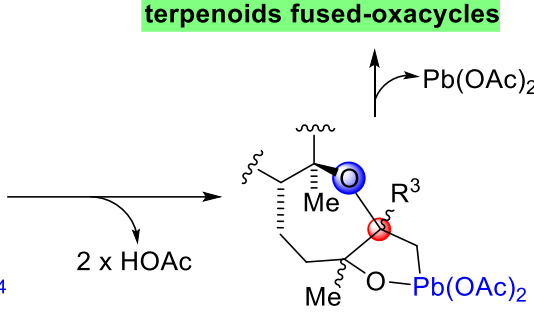

$58 a-58 d$ 56a: $R^{1}=M e ; R^{2}=H ; R^{3}=H(\beta) ; M e(\alpha) .97 \%$

56b: $\mathrm{R}^{1}=\mathrm{CH}_{2} \mathrm{OH} ; \mathrm{R}^{2}=\mathrm{H} ; \mathrm{R}^{3}=\mathrm{H}(\beta) ; \mathrm{Me}(\beta) .95 \%$

56c: $R^{1}=M e ; R^{2}=O A c ; R^{3}=H(\beta) ; M e(\beta) .92 \%$

56d: $R^{1}=M e ; R^{2}=H ; R^{3}=M e(\alpha / \beta$ mixture); $M e(\alpha) .73 \%$

Scheme 14. Oxidative coupling promoted by $\mathrm{Pb}(\mathrm{OAc})_{4}$. Adapted from ref. ${ }^{[32]}$

The coupling agent chosen for these reactions is lead tetraacetate, and the proposed mechanism starts by generating an interaction of this catalyst with the double bond and the proximal hydroxyl group, thus increasing the electrophilicity of the internal carbon in the olefin. Next, the nucleophilic hydroxyl group attacks the double bond to generate a metallaoxacycle intermediate, which finally evolves through a reductive elimination to obtain the final products 56a-56d in excellent yield.

The next example, proposed by Karunakar and co-workers, relies on the use of the catalytic properties of gold, ${ }^{[33]}$ as a key tool to achieve the synthesis of several benzooxepinones. ${ }^{[34]}$ 


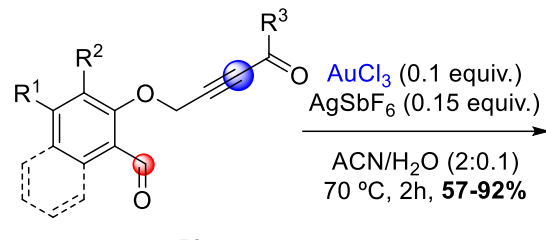

59<smiles>[R]C(=O)c1ccc(COc2c([R])c([R])c3ccccc3c2C(O)O)cc1</smiles>

61

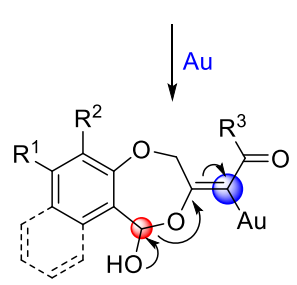

62

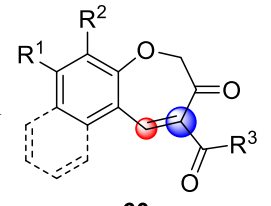

60

$\Delta^{4}$-benzooxepen-3-ones<smiles>COC</smiles>

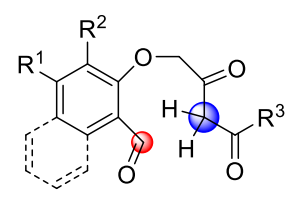

64

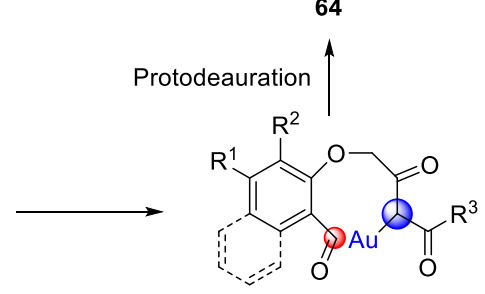

63

$\mathrm{R}^{1}=\mathrm{H}, \mathrm{Me} ; \mathrm{R}^{2}=\mathrm{H}, \mathrm{OMe} ; \mathrm{R}^{3}=\mathrm{C}_{6} \mathrm{H}_{5}, \mathrm{C}_{6} \mathrm{H}_{4} \mathrm{CH}_{2} \mathrm{CH}_{3}-p, \mathrm{C}_{6} \mathrm{H}_{4} \mathrm{~F}-p$, 1-naphtyl, $\mathrm{C}_{6} \mathrm{H}_{4} \mathrm{OCH}_{3}, \mathrm{C}_{6} \mathrm{H}_{4} \mathrm{C}\left(\mathrm{CH}_{3}\right)_{3}$-p, 2-thiophenyl

Scheme 15. $\mathrm{AuCl}_{3}$-catalyzed cyclization of ortho-O-propagyl-1-one substituted arylaldehydes 59. Adapted from ref. ${ }^{[34]}$

As depicted in Scheme 15, the method is described as a multistep procedure, where the first reaction is hydration of aldehyde 59 to generate the gem-diol intermediate 61 . Then, the gold catalyst promotes the cyclization process, providing the intermediate $\mathbf{6 2}$, in the same fashion as previously described by Chan and coworkers. $^{[35]}$ Next, a Petasis-Ferrier-like ${ }^{[36]}$ cycloreversion gives the new aldehyde 63 , which finally undergoes an aldol condensation reaction to generate the desired products.

The last entry in this section was published by Adak and coworkers, where the cyclization method is based on an intramolecular Heck reaction, following other similar approaches mentioned in the present text (Scheme 16). ${ }^{[3]}$
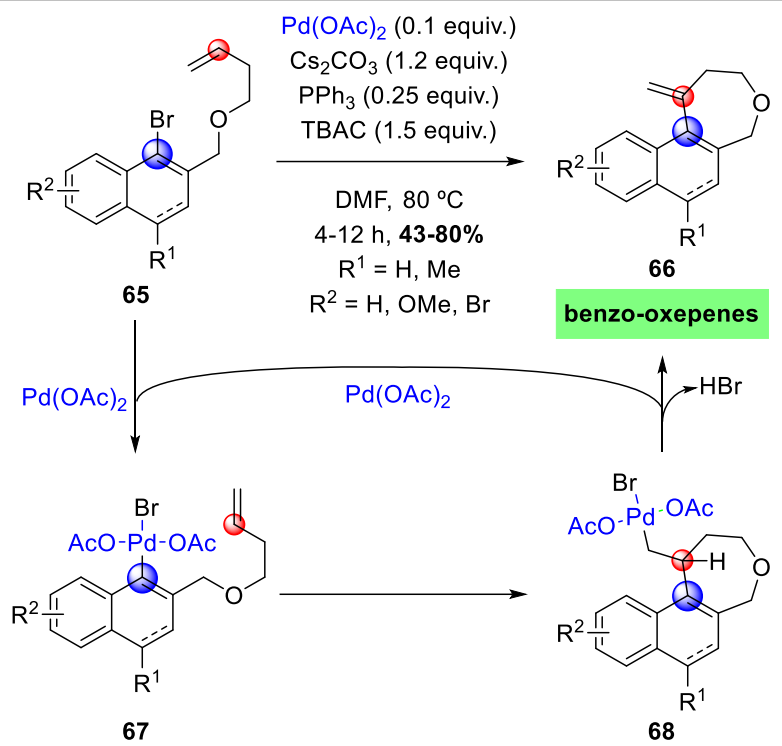

Scheme 16. Heck intramolecular coupling cyclization of bromoalkene 65 Adapted from ref. ${ }^{[37]}$

The full mechanism for this transformation has been previously well documented, ${ }^{[38]}$ so only a simplified version is presented here. The cyclization begins with the oxidative addition of $\mathrm{Pd}(\mathrm{OAc})_{2}$ to the $\mathrm{C}-\mathrm{Br}$ bond, to generate the intermediate 67 . Next, coordination and subsequent syn addition to the double-bond forms the alkylpalladium intermediate $\mathbf{6 8}$ and after this, a $\beta$-hydride elimination immediately yields the final oxepenes 66 .

\section{Ring-closing metathesis (RCM)}

In this section, we describe ring-closing metathesis reactions grouped according to the olefins and catalysts used. Furthermore, the examples in sections 3.1-3.2 are arranged according to the increasing structural complexity of the resulting oxepenes. RCM catalysts used in this part are divided into three groups and described in the following Figure 1.

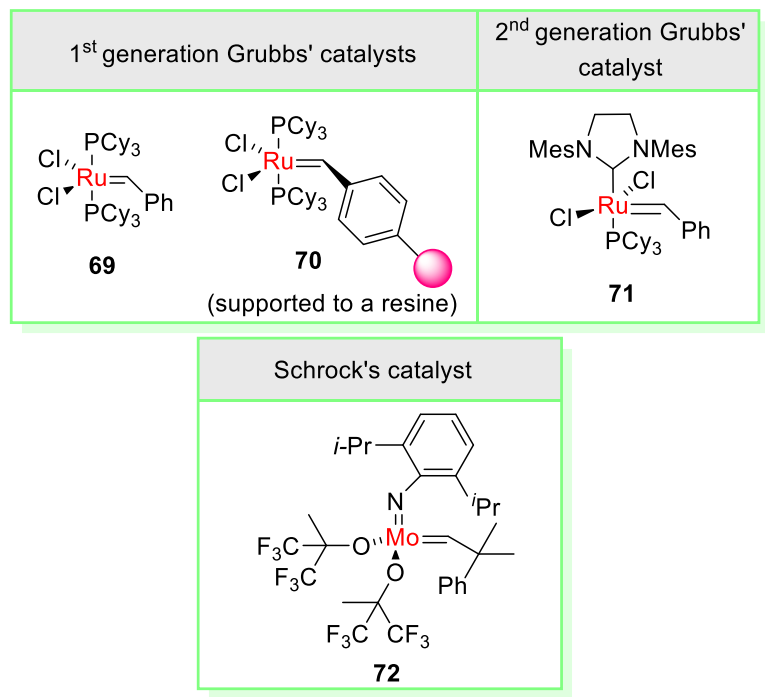

Figure 1. Catalysts used in this section for the synthesis of oxepenes through RCM. 
Nowadays widely accepted, the general RCM mechanism was proposed by Chauvin in 1971. It starts with a [2+2] cycloaddition between substrate $\mathbf{7 3}$ and catalyst alkene ligand $\mathbf{7 4}$, affording metallacyclobutane 75 (step 1). Next, a cycloreversion process occurs and the loss of volatile ethylene leads to the new metal carbene 76 (step 2). Then, an intramolecular cycloaddition forms the new metallacyclobutane 77 (step 3) and a cycloreversion expels the metal carbene catalyst, generating the cyclic alkene $\mathbf{7 8}$ (step 4) (Scheme 17). ${ }^{[39]}$

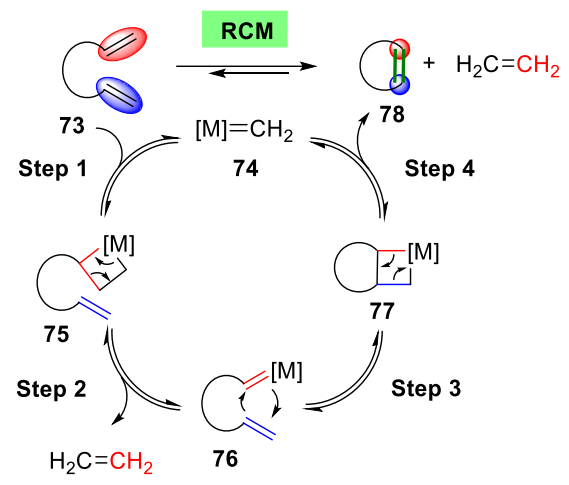

Scheme 17. RCM general mechanism. Adapted from ref. ${ }^{[39]}$

\subsection{Alkene-alkene RCM}

\subsubsection{First-generation Grubbs' catalyst}

Trans-fused polyethers, including seven-membered oxacycles, were reported in 1999 by Martín and co-workers (Scheme 18). This methodology consists of a RCM, catalyzed by Grubb's ruthenium benzylidene complex 69 , from the appropriate precursors 79. Terminal olefins with different chain lengths on the tetrahydropyran rings were prepared to synthesize rings of various sizes. Treatment of precursors 79 with catalytic amounts of first-generation Grubbs' catalyst 69 (10-20 mol\%) produced the trans-fused polyethers $\mathbf{8 0}$. The best results were obtained for the cyclizations to different oxepenes $(n=0, m=2 ; n=1, m=1)$ and oxocenes $(n=0, m=3 ; n=1, m=2 ; n=2, m=1)$ rings with yields above $95 \%$. The presence of the tetrahydropyran ring explains the effective formation of an eight-membered cycle, since it acts as a conformational restrictor and facilitates the cyclization. ${ }^{[40]}$

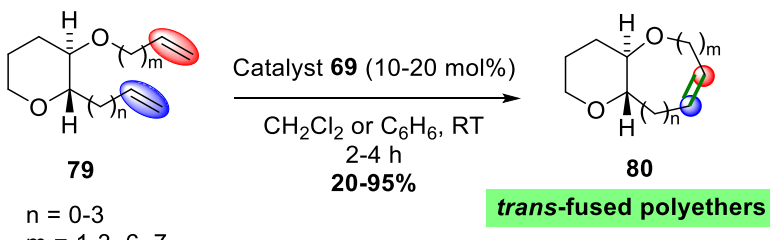

Scheme 18. Synthesis of trans-fused polyethers $\mathbf{8 0}$, including seven-membered oxacycles. Adapted from ref. ${ }^{[40]}$

In 2002, a synthesis of the ABCD ring fragment of ciguatoxins (CTXs) was published by Sasaki's group. CTXs are the predominant toxins in a type of seafood poisoning named ciguatera, which is a public health problem. They developed a convergent synthesis of the ABCD ring fragment, which includes a $B$-alkyl Suzuki cross-coupling to generate the union of $B$ and $D$ rings, a ring expansion leading to seven-membered ring $D$ and $a$ RCM to build up the oxepene ring A. Once fragment BCD is obtained, it is treated with first generation Grubbs' catalyst 69 (20 $\mathrm{mol} \%$ ) in dichloromethane at room temperature for 2.5 hours, providing the desired $A B C D$ ring framework 82 in an almost quantitative yield (Scheme 19). ${ }^{[41]}$

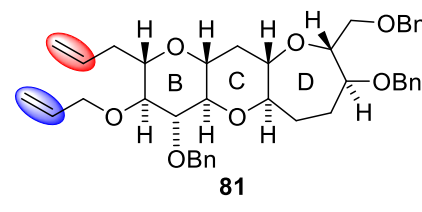

\begin{tabular}{c}
$\begin{array}{c}\text { Catalyst } 69 \\
(20 \mathrm{~mol} \%)\end{array}$ \\
\hline $\begin{array}{c}\mathrm{CH}_{2} \mathrm{Cl}_{2}, \mathrm{RT} \\
\mathbf{9 7 \%}\end{array}$
\end{tabular}

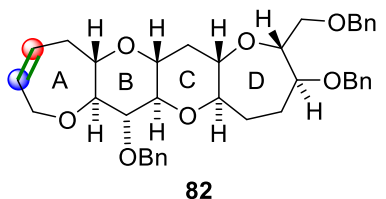

$A B C D$ ring fragment of ciguatoxins

Scheme 19. RCM in the synthesis of ring $A$ in the $A B C D$ ring fragment 82 of ciguatoxins. Adapted from ref. ${ }^{[41]}$

\subsubsection{Second-generation Grubbs' catalyst}

Glycoconjugate mimics of $\alpha$ - and $\beta$-linkage to O-GalNAc Ser/Thr are structures that have key immunological recognition features directly involved in antibody-antigen interactions, in pathogen binding, serving as tumor markers, etc. The $\alpha$ - and $\beta$-Cglucopyranosyl serines mimics (85 and 86 ) were synthesized in 2008 by Nolen's group from a common intermediate $\mathbf{8 4}$, which contains a seven-membered oxacycle (oxepenone). It was accomplished in $79 \%$ yield, through a RCM using ester 83 in presence of second-generation Grubbs' catalyst 71 (5 mol\%) in dichloromethane refluxing for $23 \mathrm{~h}$ (Scheme 20). ${ }^{[42]}$

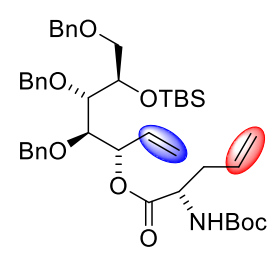

83

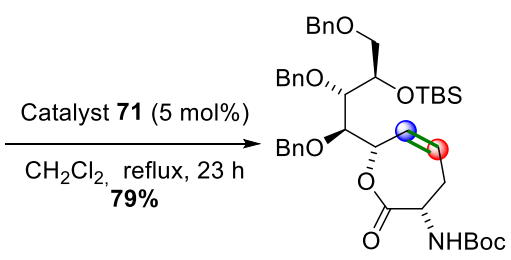

84
Oxepenone

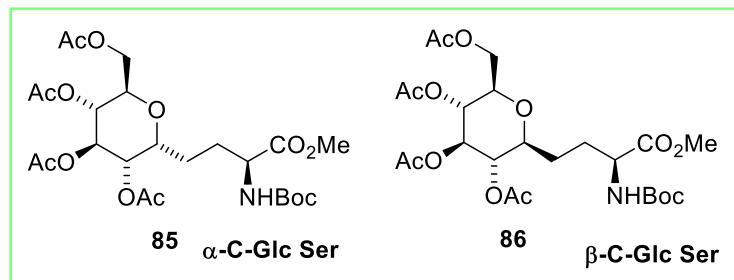

Scheme 20. Diene 83 used in the construction of oxepenone $\mathbf{8 4}$ as precursor of $\alpha$ - and $\beta$-C-glucopyranosyl serines. Adapted from ref. ${ }^{[42]}$

In 2014, Martín and coworkers achieved the enantioselective formal synthesis of (-)-isolaurepinnacin and (+)-regioloxepane A. 
The synthetic methodology is based on an intermolecular Nicholas reaction to obtain unsaturated linear ethers 87-88 and RCM to generate the cobalt complex oxepenes (Scheme 21). The $\mathrm{RCM}$ reaction occurs after the complexation of the alkyne groups with $\mathrm{Co}_{2}(\mathrm{CO})_{8}$, to avoid the enyne metathesis process. In addition, $\mathrm{Co}_{2}(\mathrm{CO})_{6}$-alkyne is used as stereochemical control agent for an isomerization process. Thus, oxepene cores are synthesized using $30 \mathrm{~mol} \%$ of the second-generation Grubbs' catalyst 71 in refluxing dichloromethane. Both cycle-complexes are produced in high yields and hexacarbonyl dicobalt was subsequently cleaved, affording oxepenes 89 and $\mathbf{9 0} .{ }^{[43]}$
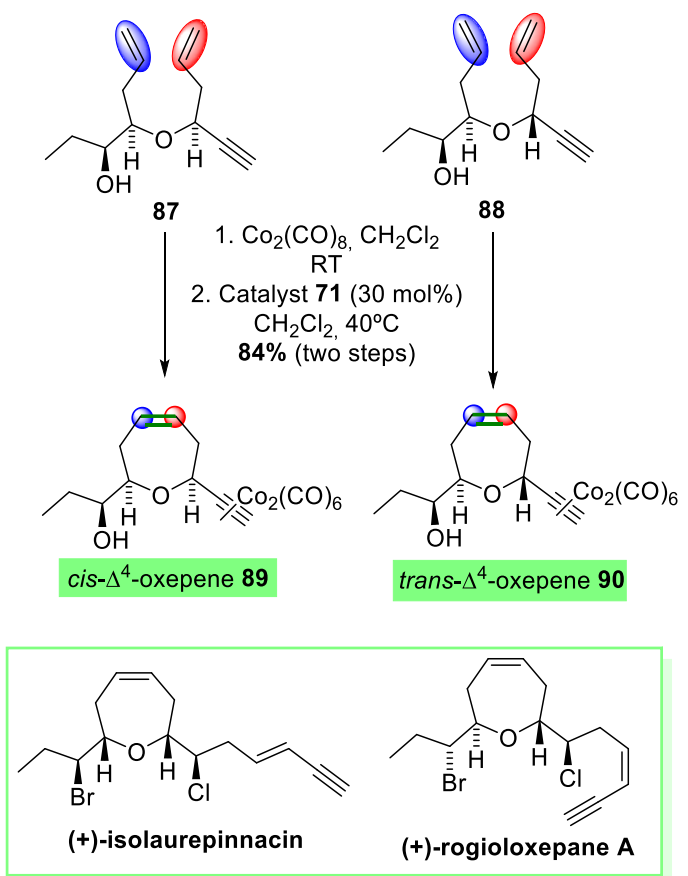

Scheme 21. Use of the $\mathrm{Co}_{2}(\mathrm{CO})_{6}$ acetylenic complex and $\mathrm{RCM}$ in the formation of seven-membered cyclic ethers 89 and $\mathbf{9 0}$. Adapted from ref. ${ }^{[43]}$

Recent work by Rainier's group has advanced in the synthesis of oxepene/oxepane motifs, in order to obtain the structural fragment of their synthetic target called adriatoxin, an analog of yessotoxin. The synthetic route started with commercially available homopropargylic alcohol and after seven steps of reaction, precursor 91 was obtained (Scheme 22). Next, an optimized RCM process generated the oxepene motif. These conditions included heating precursor 91 for $15 \mathrm{~h}$ at $60{ }^{\circ} \mathrm{C}$ in the presence of the second-generation Grubbs' catalyst 71 or using Schrock's catalyst 72 at room temperature. Both methods successfully provided oxepene 92 in similar yields (75-76\%). ${ }^{[44]}$

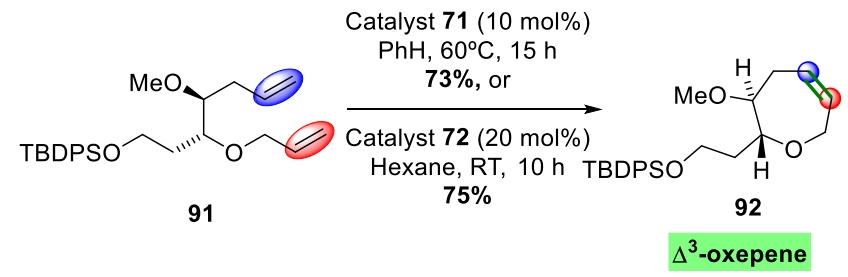

Scheme 22. Synthesis of $\Delta^{3}$-oxepene 92 using two different RCM catalysts. Adapted from ref. ${ }^{[44]}$
More complex oxepenes such as 1-indanonyl oxepanes 95 were described by Chang and colleagues in 2012. These benzo[b]oxepanes represent the structural motifs of natural products (e.g. radulanin A) and were studied because of their potential biological properties. The benzo[b]oxepane skeleton 94 is built through an intramolecular RCM using the secondgeneration Grubbs' catalyst. This is followed by a Wittig olefination of the benzaldehyde bearing the oxepene ring (Scheme 23). Both reactions use dichloromethane as solvent, allowing a one-pot reaction in higher yields than the two-step reaction process. Finally, hydrogenation of oxepene 94 , basic hydrolysis of the resulting hydrogenated ester and Friedel-Craft's intramolecular acylation are needed to arrive at 1-indanonyl oxepanes $95 .^{[45]}$

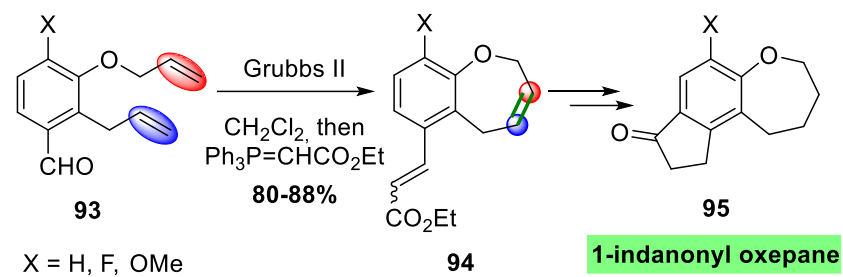

Scheme 23. RCM reaction to obtain benzo[b]oxepene 94 as precursor of 1 indanonyl oxepane 95 . Adapted from ref. ${ }^{[45]}$

\subsubsection{Takai-Utimoto-RCM}

In 2005, Rainier and colleagues completed the total synthesis of gambierol, a ladder toxin isolated from cultured cells of Gambierdiscus toxicus. After coupling A-C and F-H precursors, the ester 96 was obtained. Next, optimized protocols for TakaiUtimoto olefination and RCM avoid decomposition of the terminal olefin (Scheme 24). Then, the use of a substituted titanium alkylidene reagent in the place of the normally used methylidene reagent led to a higher yield of cyclic enol ether 98 . Therefore, titanium alkylidene from 1,1-dibromoethane provides oxepene ring 98 in $60 \%$ yield, in only one reaction step. ${ }^{[46]}$ 


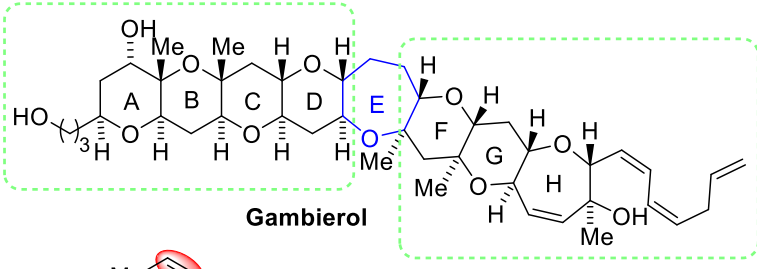

(c)

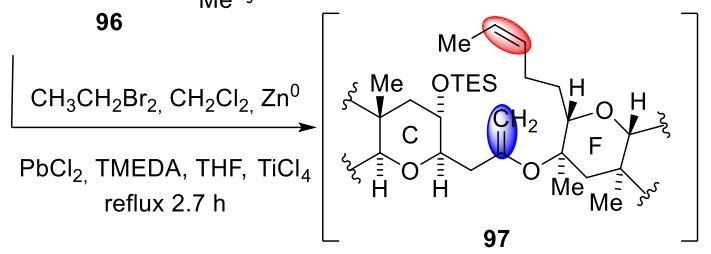

Takai-Utimoto olefination and RCM

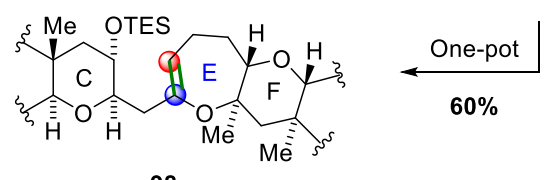

98

Scheme 24. Takai-Utimoto olefination and RCM in the synthesis of ring $E$ of gambierol. Adapted from ref. ${ }^{[46]}$

\subsection{Alkene-alkyne RCM}

Collections of natural-product inspired compounds have special interest regarding the Biology Oriented Synthesis (BIOS) concept. Among those, Waldmann's group was attracted by the oxepane scaffold and therefore developed a method for the synthesis of a library of compounds containing such cyclic ether. The key step was the ring-closing enyne metathesis reaction necessary to obtain the oxepane core (Scheme 25). Precursors 99a-99b were treated with polymer-supported first-generation Grubbs catalyst $\mathbf{7 0}$ in refluxing dichloromethane and oxepanes $\mathbf{1 0 0}$ were obtained. However, this immobilized version of the catalyst had an inferior catalytic performance and its loading was too low for the synthesis of a seven-membered oxacycle library. Then, first-generation Grubbs catalyst 69 (20 mol\%) was used and the resin 101 was added as a ruthenium scavenger, following the method developed by Breinbauer and co-workers. The oxepanes 100 were formed in the same diastereomeric ratio of the precursors $99 \mathrm{a}-99 \mathrm{~b}$, which indicates that the configuration of the enyne precursors is transferred into the oxacycles after the ring-closing enyne metathesis. ${ }^{[47]}$

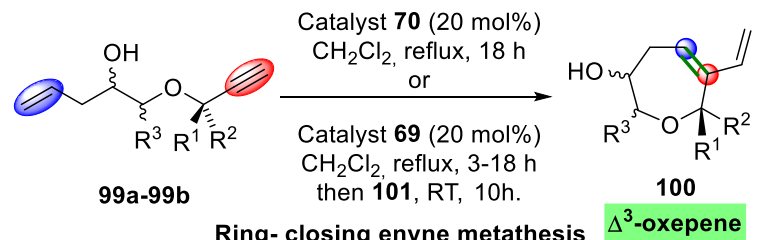

Ring-closing enyne metathesis $\Delta^{3}$-oxepene

$$
\begin{aligned}
& \text { 99a }=\mathrm{R}^{1}=\left(\mathrm{CH}_{2}\right)_{4} \mathrm{CH}_{3} \quad \text { 99b }=\mathrm{R}^{1}=\left(\mathrm{CH}_{2}\right)_{4} \mathrm{CH}_{3} \\
& R^{2}=H, R^{3}=H \\
& \{-\mathrm{OH}(\mathrm{d} . \mathrm{r}=8: 1)
\end{aligned}
$$

Scheme 25. Ring-closing enyne metathesis for construction of oxepenes $\mathbf{1 0 0}$ Adapted from ref. ${ }^{[47]}$

\section{Ring expansions}

Finally, we describe in this section the advances in oxepane synthesis through ring expansions with cyclopropanes, epoxides, and double bonds as electrophiles.

\subsection{Ring expansions of cyclopropanes}

\subsubsection{Ring expansion of cyclopropane-fused carbohydrates}

In 2003, Hoberg and co-worker reported the diastereoselective formation of oxepenes by ring expansion of cyclopropanated galactal. The method uses catalytic amounts of TMSOTf and 5.0 equiv. of a silylated nucleophile in acetonitrile, obtaining oxepenes 105 with predominant $\alpha$-stereochemistry. Ring expansion of cyclopropanes $\mathbf{1 0 2}$ proves to be successful in good to excellent yields with a wide variety of nucleophiles (Scheme 26). The reaction involves the loss of an acetate to give oxonium ion intermediate 104, which is captured by the nucleophile, leading to the $\alpha, \alpha^{\prime}$-trans- $\Delta^{4}$-oxepenes 105 . Two structural factors in the bicyclic cyclopropanated starting material are necessary: a robust protecting group and the stereochemistry at C-4 of the galactal derivatives. The stereochemical change from glucose to galactose results in a hindered top face of the oxonium ion 104 This directs the selectivity of the reaction. ${ }^{[48]}$

In a follow-up report in 2009, Hoberg and co-workers disclosed a series of addition reactions on the double bond of the oxepenes 105 and their stereochemical courses, establishing an excellent method to obtain heptanose sugars 107 (Scheme 26). The addition reactions range from epoxidations to hydroxylation through hydroboration, dihydroxylation, halogenation and bromohydrin formation (Scheme 26). ${ }^{[49]}$ 


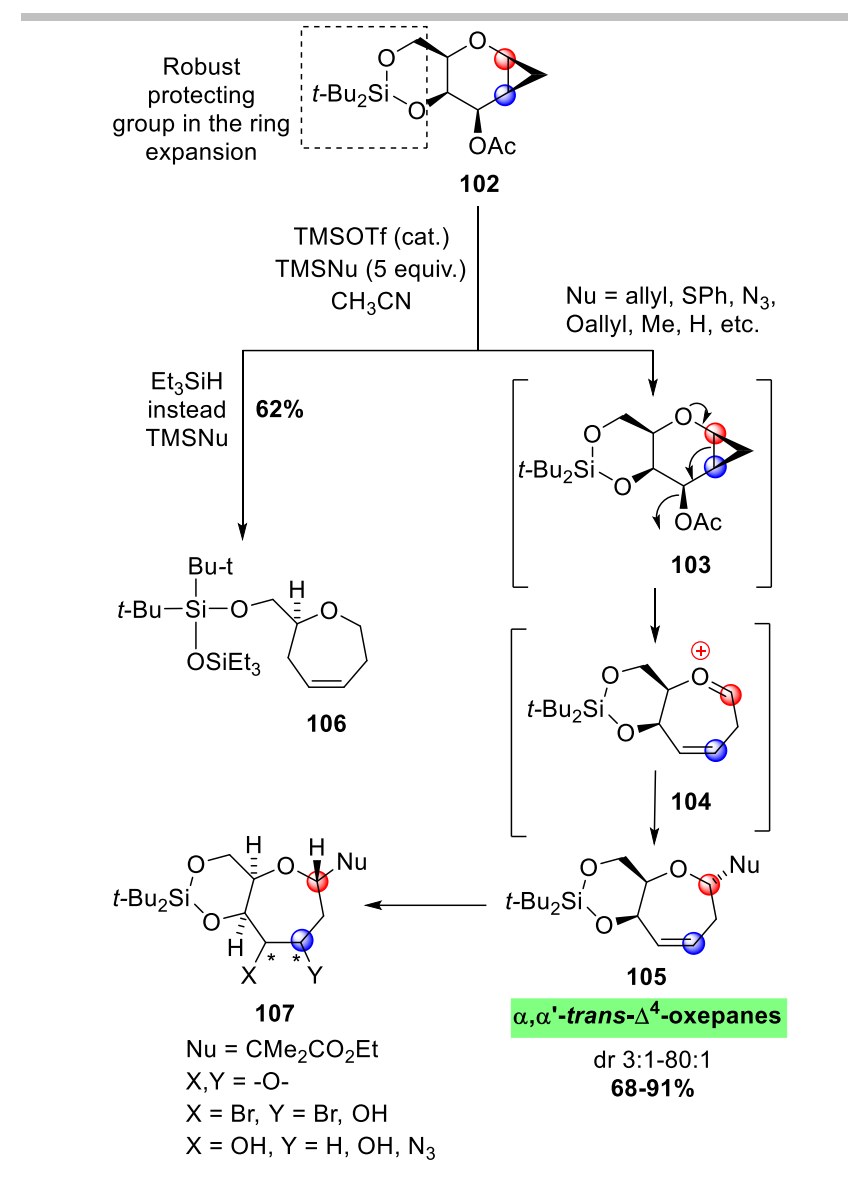

Scheme 26. TMOTf-catalyzed ring expansion of 1,2-cyclopropanated galactals 102 to furnish oxepenes 105 . Stereoselective additions to galactose-derived oxepenes to obtain heptanose sugars 107. Adapted from refs. ${ }^{[48,49]}$

Later, the core of this strategy with slight modifications was neatly applied in the synthesis of substituted oxepine derivatives.

Firstly, Harvey and co-workers reported an excellent method for the conversion of dibromocyclopropane-fused carbohydrates into 3-bromooxepines. This bromo seven-membered ring oxacycle was obtained using silver(I), which promotes a thermal ring expansion of the dibromocyclopropane 108 (Scheme 27). Treatment with silver $(\mathrm{I})$ acetate in acetic acid at $100 \stackrel{\circ}{\mathrm{C}}$ provided the anomeric acetate $\mathbf{1 1 0}$ as an $\alpha$ and $\beta$ mixture. The yield is slightly improved by replacing the acetic acid with toluene and adding an excess of sodium acetate. The 3-bromooxepine 110 was obtained in $65 \%$ yield (Scheme 27 ). ${ }^{[50]}$

Secondly, in 2014 Chandrasekaran and co-workers reported the ring expansion of carbohydrate derived vinylcyclopropanes under electrophilic conditions mediated by chloramine-T and a phasetransfer catalyst (Scheme 27). The vinylcyclopropane 111 is obtained in a few steps from $D$-glucal or $D$-galactal. Under the reaction conditions, 111 undergoes a ring expansion with a concomitant electrophilic attack on $\mathrm{BrX}$ by the vinyl moiety. The densely functionalized oxepenes $\mathbf{1 1 2}$ are obtained in good to excellent yields as a mixture of anomers. In the first step, the interhalogen compounds $(\mathrm{BrX})$ are formed in situ in catalytic amounts. These $\mathrm{BrX}$ in turn undergo addition across the double bond of vinylcyclopropane, inducing the ring expansion through a transient tight carbocation intermediate, which evolves into a stable planar oxonium intermediate. Then, attack by alcohol nucleophiles and displacement of the bromo group by NTs leads to the desired oxepenes 112 (Scheme 27). ${ }^{[51]}$

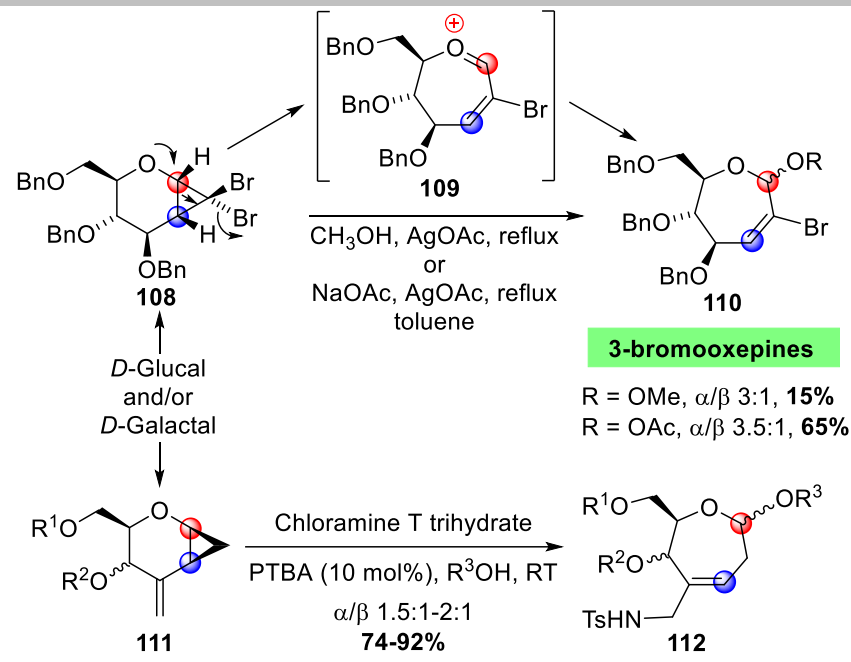

$\mathrm{R}^{1}=$ OTBS, $\mathrm{R}^{2}=\mathrm{OBn}$

$\mathrm{R}^{1}=\mathrm{R}^{2}=\mathrm{Si}\left(t-\mathrm{Bu}_{2}\right)_{2}$

$\mathrm{PTBA}=\mathrm{PhMe}_{3} \mathrm{~N}^{+} \mathrm{Br}_{3}^{-}$

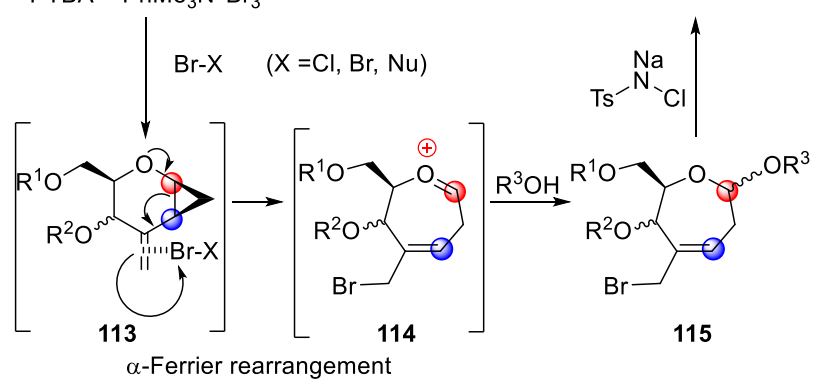

Scheme 27. Silver(I) promotes thermal ring expansion of the dibromocyclopropane 108 to obtain substituted 2-bromo oxepines $\mathbf{1 1 0}$ Chloramine-T catalyzes a ring expansion of vinylcyclopropanes $\mathbf{1 1 1}$ to provide densely functionalized oxepenes 112. Adapted from refs. ${ }^{[50,51]}$

\subsubsection{Ring expansion of cyclopropanes and further cyclization}

In 2005, Minbiole and co-workers reported the convergent synthesis of 4-keto-cis-2,7-disubstituted oxepanes 117, using a sequential addition of $\mathrm{Al}(\mathrm{OTf})_{3}$ and $\mathrm{TiCl}_{4}$ to promote the cascade ring expansion-cyclization sequence of cyclopropanol 116 and aryl and aliphatic aldehydes 118 (Scheme 28).

To rationalize the formation of oxepanes 117 , a mechanistic pathway is shown in Scheme 28. First, the formation of the stable acetal $\mathbf{1 1 9}$ is catalyzed by $\mathrm{Al}(\mathrm{OTf})_{3}$, and then $\mathrm{TiCl}_{4}$ activates this acetal to generate an oxonium species 121 , which is attacked by an alkoxycyclopropane, triggering the ring expansion and further Prins-type cyclization to furnish the desired oxepanes 117 . The method requires the presence of two Lewis acids and no adverse effect was observed. ${ }^{[52]}$ 


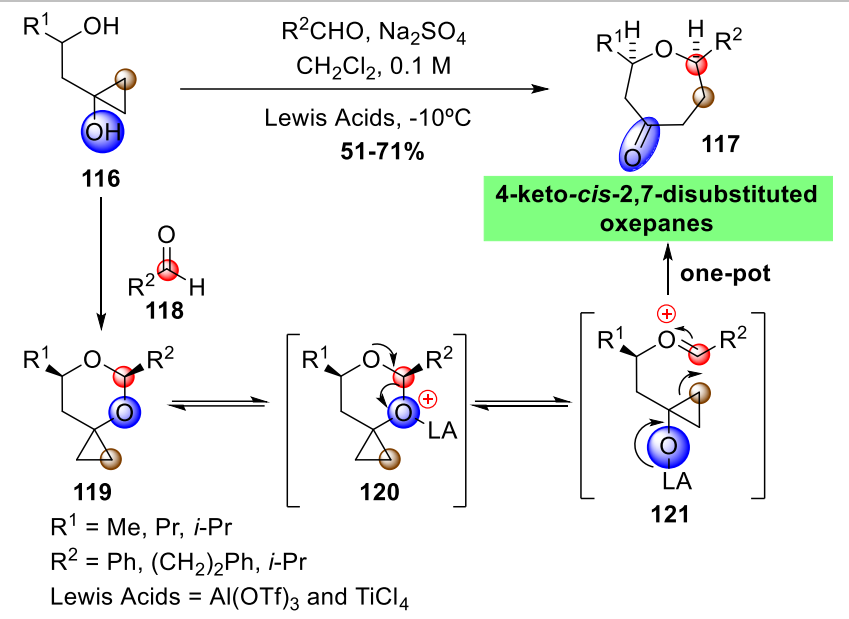

Scheme 28. $\mathrm{Al}(\mathrm{OTf})_{3}$ and $\mathrm{TiCl}_{4}$ promote a cascade ring expansion-cyclization sequence of cyclopropanol 116 and aryl and aliphatic aldehydes 118, to yield 4-keto-cis-2,7-disubstituted oxepanes 117. Adapted from ref. ${ }^{[52]}$

In 2017, Liu and co-workers reported an $\mathrm{Au}(\mathrm{I})$-catalyzed transformation by cycloaddition of 1,6-enynes 122 with diazo ketones 123 into 3-cyclopropyl-2-en-1-ones 124, and then $\mathrm{Rh}(\mathrm{I})$ mediated ring expansion and cyclization for the synthesis of oxepines 125. In this particular case, the alkyl- or ortho-arylsubstituted diazo ketones 123 surprisingly led to sevenmembered ring oxacycles 125 , via unexpected $[2+2+3]$ cycloaddition. The mechanism for this transformation is described in Scheme 29. It is known that 1,6-enynes form cyclopropyl gold carbenes 126 in the presence of gold catalyst. This carbene is then intercepted by diazo ketone $\mathbf{1 2 3}$ to produce the bicyclic enone 124, as a Z/E mixture of isomers. Next, and before the ring expansion, the $\mathrm{Rh}(\mathrm{I})$ catalyst enables a complete $\mathrm{Z} \rightarrow \mathrm{E}$ isomerization of enone 124 , leading a cyclopropane cleavage to form intermediate 127. A 1,3-Rh-shift of allyl species 127 generates six-membered carbocycles $\mathbf{1 2 8}$, with a C-bound $\mathrm{Rh}$ enolate that evolves into a more reactive O-bound enolate 129. This O-bound enolate has a 16-electron configuration, being favorable for the final reductive elimination that leads to oxepines $125 .{ }^{[53]}$

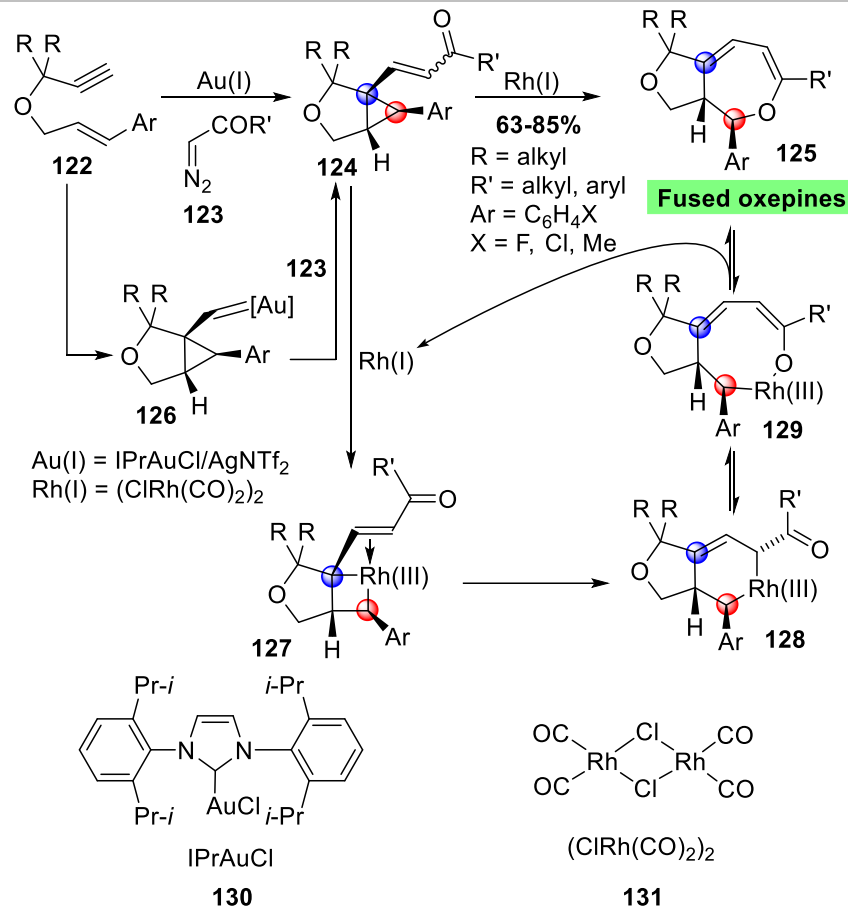

Scheme 29. A sequential route to oxepines 125 from 1,6-enynes 122 and diazo ketones 123 through gold and rhodium catalysis. Adapted from ref. ${ }^{[53]}$

In 2018, Hawkins and co-workers, exploited a method previously developed by them, ${ }^{[54]}$ in combination with a cyclization under Mitsunobu conditions, ${ }^{[55]}$ to get access to the oxepine-fused flavone 133. ${ }^{[56]}$

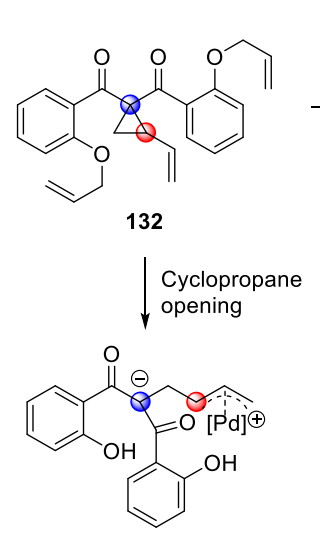

134

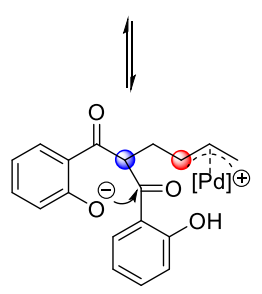

135

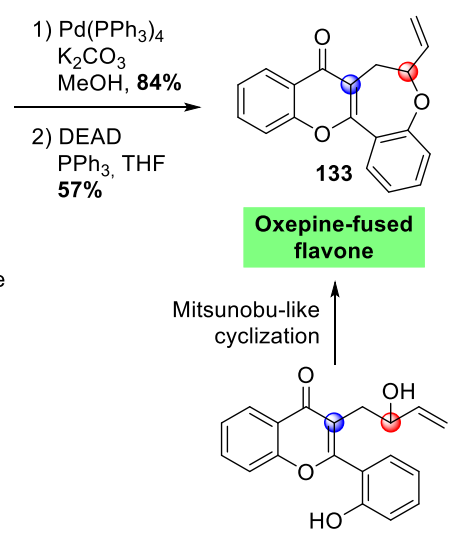

137

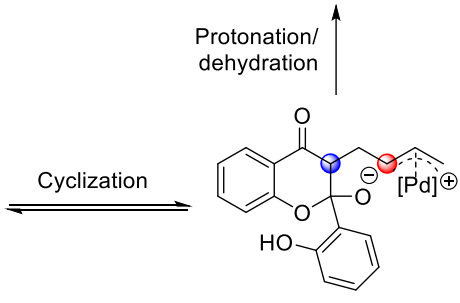

136
Scheme 30. Synthesis of oxepine-fused flavone 133 using Mitsunobu conditions. Adapted from ref. ${ }^{[56]}$ 
As depicted in Scheme 30, the first reaction transforms the cyclopropane 132 into the alcohol 137. This process takes place via the palladium-promoted cyclopropane opening, and the subsequent nucleophilic attack from the phenolate to the ketone in $\mathbf{1 3 5}$ to generate the intermediate 136, which finally undergoes a protonation and dehydration to yield the compound 137. At this point, a cyclization reaction under Mitsunobu conditions completed the synthetic route to the oxepine-fused flavone 133. In 2019, Hou, Gou and co-workers reported a sequence involving an intramolecular ring opening of cyclopropanes as a key step in forming 4-benzoyl-3,4-dihydrobenzo[b]oxepin-5(2H)-one derivatives 139 (Scheme 31). ${ }^{[57]}$

The reaction is promoted by stoichiometric $\mathrm{AlCl}_{3}$ in acetonitrile at $82{ }^{\circ} \mathrm{C}$, leading to benzoannulated seven-membered $\mathrm{O}$ heterocycles in excellent yields (up to 92\%). Electrophilic activation of the carbonyl in cyclopropane 138, through complexation by $\mathrm{AlCl}_{3}$, generates the intermediate 140 . This is then attacked by the proximal oxygen of the adjacent phenol. Next, ring opening of the cyclopropane and cyclization take place to provide a mixture of enol 141 and predominantly the ketone 139.

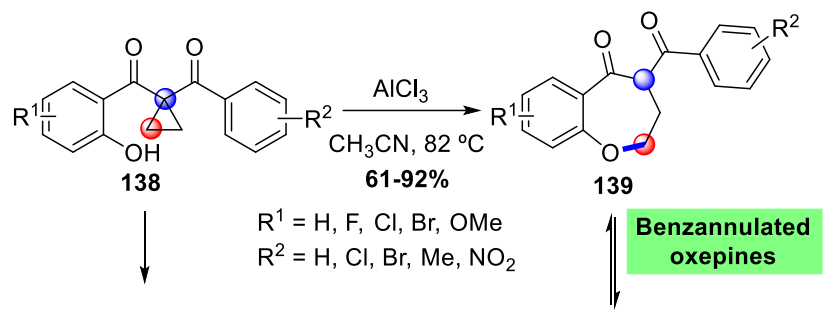

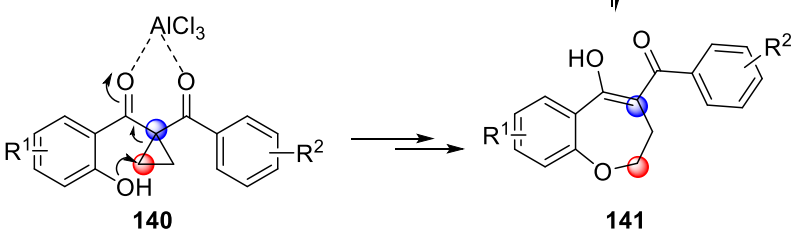

Scheme 31. Synthesis of benzannulated seven-membered O-heterocycles (139 and 141) via the intramolecular ring-opening cyclization of cyclopropanes. Adapted from ref.[57]

\subsection{Ring expansions of epoxides}

In 2002, Grée and co-workers reported the ring expansion of bicyclic epoxy alcohols, via a new rearranged organofluorine compound, leading to 2-fluoro oxepenes 143 promoted by DAST $\left(\mathrm{Et}_{2} \mathrm{NSF}_{3}\right)$. The ring expansion of cyclohexene oxide 142 is favored by the presence of the oxygen in the epoxide and the nature of the substituents at $R^{3}$. The oxygen and the substituents at $\mathrm{R}^{3}$ are necessary to stabilize the intermediates of the rearrangement products. The reaction with DAST of the corresponding cyclopropane related to $\mathbf{1 4 2}$ shows no traces of the ring-expanded carbocycles (Scheme 32). ${ }^{[58]}$
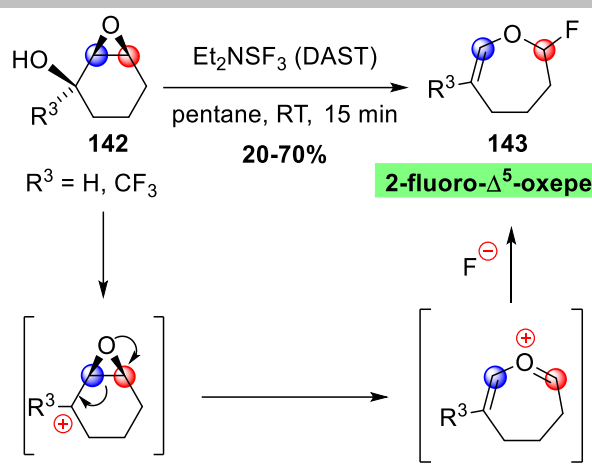

2-fluoro- $\Delta^{5}$-oxepenes

144

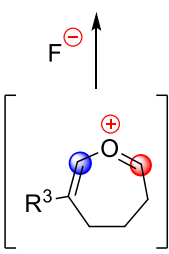

145

Scheme 32. DAST promotes the synthesis of 2-fluoro $\Delta^{5}$-oxepenes 127 Adapted from ref. ${ }^{[58]}$

In 2004, Shimizu and co-workers reported a Cope rearrangement-mediated synthesis of dihydrooxepines 147 from oxiranes 146 heated at $100^{\circ} \mathrm{C}$. They developed an easy synthetic pathway to $\mathrm{CF}_{3}$-substituted seven-membered oxacycles, which involves stereoselective preparation of cis-bis(alkenyl)oxiranes 146 followed by the Cope rearrangement. Trans-isomers of 146 cannot undergo this. The nature of $E$ (electrophile) is key to favoring and accelerating the Cope-rearrangement. Therefore, bulkiness of substituent $\mathrm{E}$ seems to close both terminal $\mathrm{sp}^{2}$ carbons, accelerating the rearrangement (Scheme 33). These oxepines were successfully modified to introduce aryl, alkenyl and alkynyl to provide oxacycles 149 , besides obtaining hydrogenated oxepanes 150 and dehydrogenated oxepines 151 . These oxepines 149 are obtained in very good yields via a Pd-catalyzed cross-coupling reaction of the metalated oxepines 147 with the corresponding halides (Scheme 33). The disubstituted oxepanes 150 are obtained with high cis-selectivity and yields after hydrogenation. The treatment with $D D Q$ in toluene drives an efficient dehydrogenation to provide the oxidated oxacycle 151, in excellent yield (Scheme 33). ${ }^{[59]}$
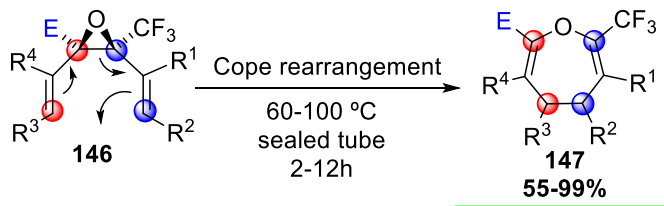

Dihydrooxepines

$\mathrm{E}=\mathrm{H}, \mathrm{Me}, \mathrm{SnMe}_{3}, \mathrm{TMS}, \mathrm{TBS}, \mathrm{CO}_{2} \mathrm{Me}, \mathrm{Bn}, \mathrm{BO}_{2} \mathrm{C}_{2} \mathrm{Me}_{4}, \mathrm{C}(\mathrm{OH}) \mathrm{Ph}_{2}$ $\mathrm{R}^{1}, \mathrm{R}^{2}, \mathrm{R}^{3}, \mathrm{R}^{4}=\mathrm{H}, \mathrm{Ph},-\left(\mathrm{CH}_{2}\right)_{3} \mathrm{O}-$

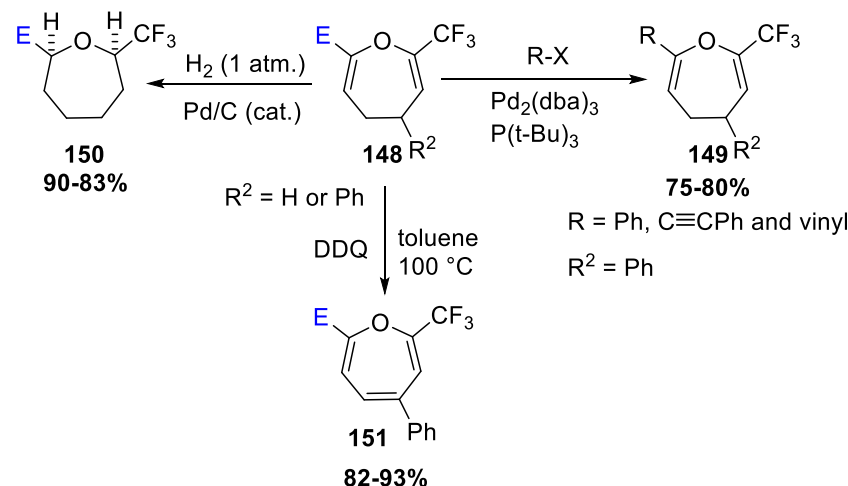

Scheme 33. Cope rearrangement to obtain unsaturated seven-membered rings 147. Synthesis of substituted oxepanes 151 and oxepines 151. Adapted from ref. ${ }^{[59]}$ 


\subsection{Ring expansions of vinylcycloalkanols}

In 2015, Silva and co-workers reported the synthesis of benzenefused substituted oxepanes (155, 157 and 158), using a [hydroxy[(tosyloxy)iodo]benzene-promoted (HITB-) cascade ringexpansion sequence of bicyclic vinylalkenols (Scheme 34). The cascade sequence involves HIBT vinyl activation, ring expansion/oxidation, elimination and further methanol addition to afford products 155, 157 and 158. HIBT promotes ring expansion through forming carbocation 153. A reductive solvolysis to the intermediate species 154 provides the oxepane 155 which is the starting material to path $\mathrm{A}$ and $\mathrm{B}$. Methanol addition to the ketone group under acidic conditions affords oxepane product 157 (path A). Alternatively, oxepane $\mathbf{1 5 5}$ may pass through an elimination of the methoxy group, to leave a non-isolated enone intermediate. This is followed by methanol addition under reaction conditions to produce 158 via path $B$ (Scheme 34). ${ }^{60]}$

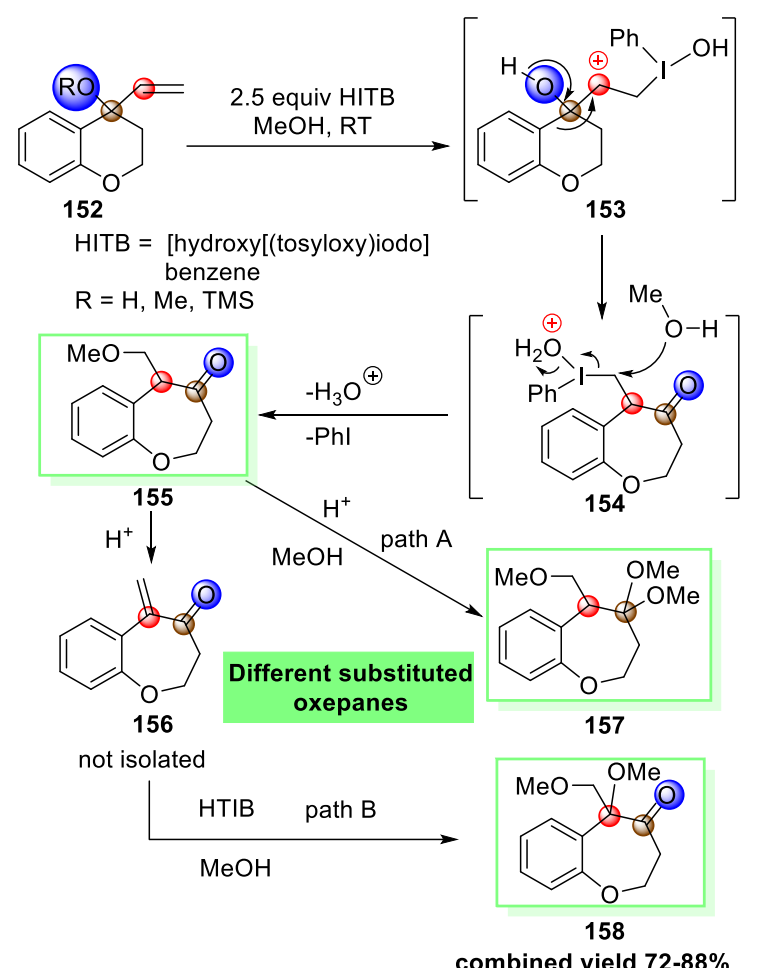

Scheme 34. HITB-promoted cascade ring-expansion sequence of bicyclic vinylalkenols to provide different substituted oxepanes 155, 157 and 158 . Adapted from ref. ${ }^{[60]}$

\subsection{Ring expansions of cyclohexanone}

In 2013, Nicolaou and co-workers reported the access to functionalized 4,5-dihydrooxepynes 161 from cyclohexanones 159 in a three-steps sequence, regioselective Baeyer-Villiger, enol phosphate formation and $\mathrm{C}-\mathrm{C}$ bond formation. The regioselective Baeyer-Villiger with $m$-CPBA gave the enol lactone in a poor yield of $15 \%$. However, the combination of bis(trimethylsilyl)peroxide (BTSP) and $\mathrm{SnCl}_{4}$, in the presence of ligand $A$, led the desired enol lactone in $83 \%$ yield. The Lewis acid is necessary to get a substrate activation that improve the conversion avoiding product decomposition. On the other hand, the presence of the ligand $A$ is critical to temper the Lewis acidity of $\mathrm{SnCl}_{4}$.
The authors chose the phosphate group over the more common triflate group due the bigger and well-known stability. The resulting enolphosphate $\mathbf{1 6 0}$ provide a common intermediate in a series of C-C bond forming reactions leading a wide family of functionalized 4,5-dihydrooxepine 161. For example, Ni-catalyzed Negishi coupling leading the ethyl substituted dihydrooxepine 166. Using $\mathrm{PdCl}_{2}$ (dppf) as catalyst, 3-thienyl and alkynyl can be introduced in the oxepine core with high yields (products 163 and 165 , respectively). The same palladium catalyst is very useful to lead an ester group, after the replacement of the phosphate group, with a $52 \%$ yield (product 164). ${ }^{[61]}$

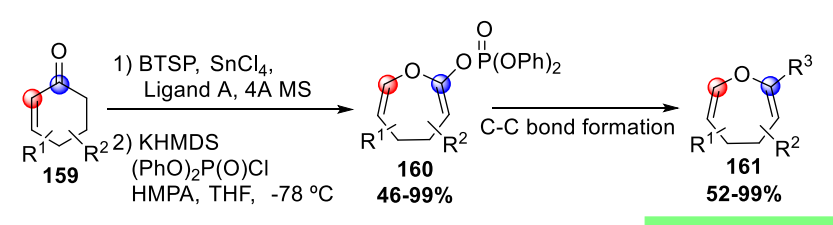

$\begin{array}{ll}\mathrm{NHR} & \mathrm{R}=\mathrm{H} \text {, racemic Ligand } \mathrm{A} \\ \mathrm{R}=\mathrm{Ts}, \text { racemic Ligand } \mathrm{B}\end{array}$ Dihydrooxepines

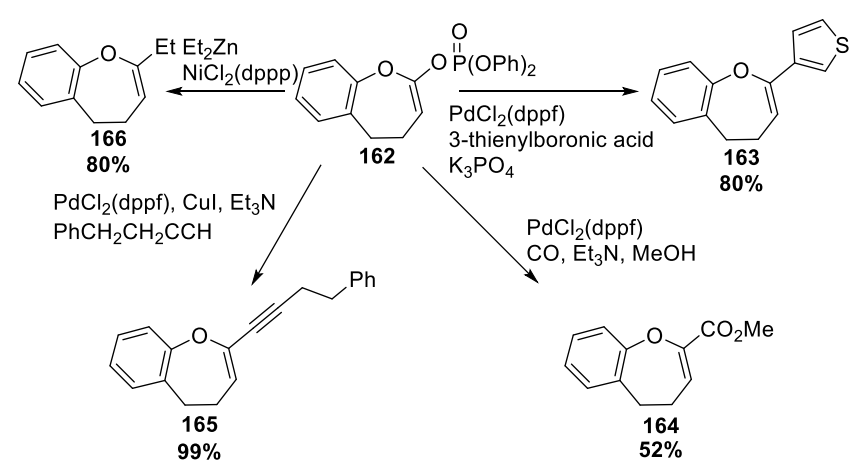

Scheme 35. Three-step approach for the synthesis of functionalized 4,5 dihydrooxepines 161 from cyclohexanones 159. Regioselective Baeyer-Villiger, enol phosphate formation, and Pd-catalyzed C-C bond formation. Adapted from ref. [61]

In summary, this minireview has covered the different methodologies developed during the past two decades. A wide range of methods have been developed to gain access to seven membered ring oxacycles (saturated and unsaturated). These strategies are based on cyclizations, ring-closing metathesis, conjugate additions and ring expansions.

The cyclization occurs between a precursor nucleophile and simple electrophiles in either an inter- or intramolecular manner, through a cationic or radical pathway. These processes show high efficiency and stereoselectivity. In the RCM and conjugate additions, a precursor with the appropriate functionalities and correct stereochemistry triggers the oxepane synthesis. Finally, the behavior of both methods is utilized in the ring expansions described. Many of the ring-expansion examples lead to an oxonium cation intermediate that undergoes inter- or intramolecular attack. In other cases, the precursor has suitable stereochemistry in the final oxacycle, so ring expansion is the way to achieve the right seven-membered ring size.

Some classical methods have been revisited, but the attention was mostly focused on alternative approaches. Although the number of examples of this kind of cycles is clearly less than their five- and six-membered counterparts, this text presents a remarkable variety of strategies, probably because of the greater 
difficulty in synthesizing these medium-size oxacycles. Thus, the number of degrees of freedom and entropy values have forced the researchers to envision new ways to gain access to these interesting structures.

\section{Acknowledgments}

This research was supported by the Ministerio de Ciencia, Innovación y Universidades (MCIU), la Agencia Estatal de Investigación (AEI), Fondo Europeo de Desarrollo Regional (FEDER) and ACIISI (Gobierno de Canarias) (PGC2018-094503B-C22 and ProlD2017010118). V. S. thanks the Spanish MCIU for an F.P.U. fellowship. D. A. C. thanks the Cabildo de Tenerife for a postdoctoral Agustín de Betancourt contract. The manuscript was edited by Guido Jones, also funded currently by Cabildo de Tenerife under the TFinnova Program, supported by MEDI and FDCAN.

Keywords: oxepane $\cdot$ oxepene $\cdot$ seven-membered ring $•$ oxepine $\cdot$ medium oxacycle

[1] R. M. Kanojia, E. Chin, C. Smith, R. Chen, D. Rowand, S. D. Levine, M. P. Wachter, R. E. Adams, D. Hahn, J. Med. Chem. 1985, 28 796-803.

[2] A. Nadin, C. Hattotuwagama, I. Churcher, Angew. Chemie Int. Ed. 2012, 51, 1114-1122.

[3] V. A. Stonik, Acta Naturae 2009, 1, 15-25.

[4] T. Asai, S. Otsuki, H. Sakurai, K. Yamashita, T. Ozeki, Y. Oshima, Org. Lett. 2013, 15, 2058-2061.

[5] I. Kadota, Y. Yamamoto, Acc. Chem. Res. 2005, 38, 423-432.

[6] H. Oguri, M. Hirama, T. Tsumuraya, I. Fujii, M. Maruyama, H. Uehara, Y. Nagumo, J. Am. Chem. Soc. 2003, 125, 7608-7612.

[7] A. K. Ghosh, A. J. Tomaine, K. E. Cantwell, Synthesis (Stuttg). 2017, 49, 4229-4246.

[8] F. E. McDonald, X. Wang, B. Do, K. I. Hardcastle, Org. Lett. 2000, 2, 2917-2919.

[9] D. D. Díaz, J. M. Betancort, F. R. P. Crisóstomo, T. Martín, V. S. Martín, Tetrahedron 2002, 58, 1913-1919.

[10] S.-H. Kim, S.-J. Oh, P.-S. Ho, S.-C. Kang, K.-J. O, C.-M. Yu, Org. Lett. 2008, 10, 265-268.

[11] A. Castaneda, D. J. Kucera, L. E. Overman, J. Org. Chem. 1989, 54, 5695-5707.

[12] K. A. Nguyen, M. S. Gordon, G. T. Wang, J. B. Lambert, Organometallics 1991, 10, 2798-2803.

[13] D. A. Cruz, V. Sinka, V. S. Martín, J. I. Padrón, J. Org. Chem. 2018, 83, 12632-12647.

[14] Y. Sun, Y. Huang, M. Li, J. Lu, N. Jin, B. Fan, R. Soc. Open Sci. 2020, 5, 180740.

[15] T. Rüther, V. M. Hultgren, B. P. Timko, A. M. Bond, W. R. Jackson, A. G. Wedd, J. Am. Chem. Soc. 2003, 125, 10133-10143.

[16] A. Chen, H. Yu, J. Yan, H. Huang, Org. Lett. 2020, 22, 755-759.

[17] M.-Y. Chang, Y.-T. Hsiao, K.-H. Lai, J. Org. Chem. 2018, 83, 14110-14119.

[18] C. Mukai, M. Ohta, H. Yamashita, S. Kitagaki, J. Org. Chem. 2004 69, 6867-6873.

[19] C. Mukai, H. Yamashita, M. Hanaoka, Org. Lett. 2001, 3, 33853387.

[20] S. Tripathi, B. G. Roy, M. G. B. Drew, B. Achari, S. B. Mandal, J.
Org. Chem. 2007, 72, 7427-7430

[21] K. V Gothelf, K. A. Jørgensen, Chem. Commun. 2000, 1449-1458.

[22] M. L. Lanier, A. C. Kasper, H. Kim, J. Hong, Org. Lett. 2014, 16, 2406-2409. https://pubs.acs.org/doi/abs/10.1021/ol500773w. Notice to readers: further permissions related to the material excerpted should be directed to the ACS.

[23] Y. Fall, G. Gomez, C. Fernandez, Tetrahedron Lett. 1999, 40, 8307-8308.

[24] Y. Fall, B. Vidal, D. Alonso, G. Gómez, Tetrahedron Lett. 2003, 44, 4467-4469.

[25] R. C. Betori, B. R. McDonald, K. A. Scheidt, Chem. Sci. 2019, 10, 3353-3359.

[26] N. Hori, H. Matsukura, T. Nakata, Org. Lett. 1999, 1, 1099-1101.

[27] M. P. Sibi, K. Patil, T. R. Rheault, European J. Org. Chem. 2004, 2004, 372-384.

[28] T. Colacot, New Trends in Cross-Coupling, Royal Society Of Chemistry, Cambridge, 2014.

[29] R. F. Heck, J. Am. Chem. Soc. 1969, 91, 6707-6714.

[30] A. O. King, N. Okukado, E. Negishi, J. Chem. Soc. Chem. Commun. 1977, 683-684.

[31] J. K. Stille, Angew. Chemie Int. Ed. English 1986, 25, 508-524.

[32] H. Bouanou, J. A. Gil, R. Alvarez-Manzaneda, R. Chahboun, E. Alvarez-Manzaneda, J. Org. Chem. 2016, 81, 10002-10008.

[33] M. Rudolph, A. S. K. Hashmi, Chem. Soc. Rev. 2012, 41, 24482462.

[34] N. S. V. M. R. Mangina, S. Suresh, B. Sridhar, G. V Karunakar, Org. Biomol. Chem. 2016, 14, 3526-3535.

[35] E. M. L. Sze, W. Rao, M. J. Koh, P. W. H. Chan, Chem. - A Eur. J. 2011, 17, 1437-1441.

[36] A. B. Smith, R. J. Fox, T. M. Razler, Acc. Chem. Res. 2008, 41, 675-687.

[37] A. K. Adak, A. Mandal, S. K. Manna, S. K. Mondal, A. Jana, D. Ghosh, D. Kundu, S. Samanta, J. K. Ray, Synth. Commun. 2016, 46, 452-459.

[38] A. B. Dounay, L. E. Overman, Chem. Rev. 2003, 103, 2945-2964.

[39] P. Jean-Louis Hérisson, Y. Chauvin, Die Makromol. Chemie 1971, 141, 161-176.

[40] M. Delgado, J. D. Martín, J. Org. Chem. 1999, 64, 4798-4816.

[41] M. Sasaki, M. Ishikawa, H. Fuwa, K. Tachibana, Tetrahedron 2002, 58, 1889-1911.

[42] E. G. Nolen, L. A. Donahue, R. Greaves, T. A. Daly, D. R. Calabrese, Org. Lett. 2008, 10, 4911-4914.

[43] J. Rodríguez-López, N. Ortega, V. S. Martín, T. Martín, Chem. Commun. 2014, 50, 3685-3688.

[44] C. Osei Akoto, J. Rainier, Synthesis (Stuttg). 2019, 51, 3529-3535.

[45] M.-Y. Chang, N.-C. Lee, Synlett 2012, 23, 867-872.

[46] H. W. B. Johnson, U. Majumder, J. D. Rainier, J. Am. Chem. Soc. 2005, 127, 848-849.

[47] S. Basu, H. Waldmann, Bioorg. Med. Chem. 2014, 22, 4430-4444.

[48] R. Batchelor, J. O. Hoberg, Tetrahedron Lett. 2003, 44, 9043-9045.

[49] R. Batchelor, J. E. Harvey, P. T. Northcote, P. Teesdale-Spittle, J. O. Hoberg, J. Org. Chem. 2009, 74, 7627-7632.

[50] R. J. Hewitt, J. E. Harvey, J. Org. Chem. 2010, 75, 955-958.

[51] V. Ganesh, T. Kundu, S. Chandrasekaran, Tetrahedron 2014, 70, 7268-7282.

[52] K. E. O'Neil, S. V Kingree, K. P. C. Minbiole, Org. Lett. 2005, 7, 515-517.

[53] B. S. Kale, H.-F. Lee, R.-S. Liu, Adv. Synth. Catal. 2017, 359, 402409. 
[54] R. J. Smith, D. Nhu, M. R. Clark, S. Gai, N. T. Lucas, B. C. Hawkins, J. Org. Chem. 2017, 82, 5317-5327.

[55] O. Mitsunobu, Synthesis (Stuttg). 1981, 1981, 1-28.

[56] S. A. French, M. R. Clark, R. J. Smith, T. Brind, B. C. Hawkins, Tetrahedron 2018, 74, 5340-5350.

[57] D. Cao, K. Zhang, R. An, H. Xu, S. Hao, X. Yang, Z. Hou, C. Guo, Org. Lett. 2019, 21, 8948-8951.

[58] P. Lakshmipathi, D. Grée, R. Grée, Org. Lett. 2002, 4, 451-454.

[59] M. Shimizu, T. Fujimoto, X. Liu, T. Hiyama, Chem. Lett. 2004, 33, 438-439.

[60] S. Silva, A. Torre, J. de Carvalho, A. Ruiz, L. Silva, Molecules 2015, 20, 1475-1494.

[61] K. C. Nicolaou, R. Yu, L. Shi, Q. Cai, M. Lu, P. Heretsch, Org. Lett. 2013, 15, 1994-1997. 


\section{Entry for the Table of Contents}

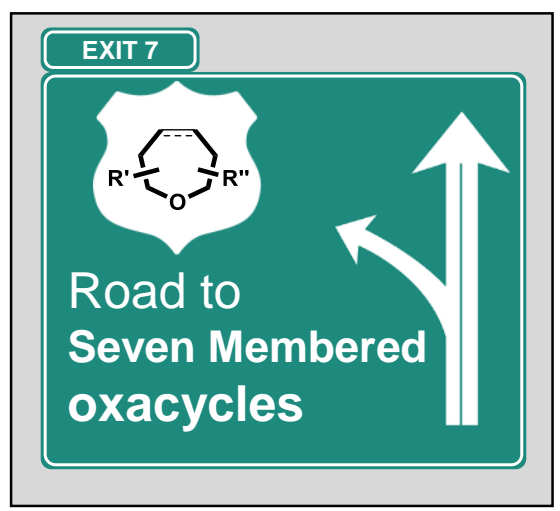

This minireview cover the recent advances and methodologies, developed during the past two decades, in the synthesis of sevenmembered ring oxacycles. A wide range of methods have been developed to gain access to these oxacycles (saturated and unsaturated). These strategies are based on cyclizations (oxocarbenium ion, carbocation or iminium-type species), ring-closing metathesis, conjugate additions and ring expansions (cyclopropanes and epoxides).

Key topic: Seven-membered oxacycles.

Institute and/or researcher Twitter usernames: https://twitter.com/IPNA CSIC 